Canadian

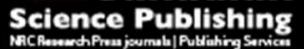

Canadian Journal of Civil Engineering Revue canadienne de génie civil

\title{
Impact of a large cylindrical roughness on tidal bore propagation
}

\begin{tabular}{|r|l|}
\hline Journal: & Canadian Journal of Civil Engineering \\
\hline Manuscript ID & cjce-2015-0557.R2 \\
\hline Danuscript Type: & Article \\
\hline Complete List of Authors: & $\begin{array}{l}\text { Yeow, Swee Chia; The University of Queensland, Civil Engineering } \\
\text { Chanson, Hubert; The University of Queensland, School of Civil Engineering } \\
\text { Wang, Hang; The University of Queensland, Civil Engineering }\end{array}$ \\
\hline Keyword: & $\begin{array}{l}\text { tidal bore, Large roughness element, Physical modelling, Unsteady } \\
\text { turbulent mixing }\end{array}$ \\
\hline \multicolumn{2}{|c}{} \\
\hline
\end{tabular}

\section{SCHOLARONE ${ }^{\text {m }}$}

Manuscripts 


\section{IMPACT OF A LARGE CYLINDRICAL ROUGHNESS ON TIDAL BORE PROPAGATION}

S.C. Yeow, Research student, H. Chanson, Professor, and H. Wang, Research fellow The University of Queensland, School of Civil Engineering Brisbane QLD 4072, Australia

Ph.: (61 7) 33653516 - Fax: (61 7) 33654599 - Email: h.chanson@uq.edu.au

Word count : 5,450 words. 
Abstract: A tidal bore is a hydrodynamic shock, surging upstream in some shallow-water bays and estuaries during the flood tide under large tidal range. This study investigates experimentally the propagation of tidal bores over a large cylindrical roughness element, representative of damaged bridge pier foundation. In the initially steady flow, the large cylindrical element generated a wake region, with extents comparable to steady flow literature. During the tidal bore propagation, the presence of the element had negligible effect on the freesurface properties, but a significant impact in terms of the instantaneous velocity and Reynolds stresses. This resulted in longer transient recirculation both upstream and downstream of the element and larger maximum velocity recirculation magnitudes, as well as enhanced turbulent stress levels and potential bed erosion around the large element, within two diameters from the element centre. The results showed the potential development of a large scour hole around the cylindrical element.

Keywords: Tidal bores, Large roughness element, Physical modelling, Unsteady turbulent mixing.

Résumé: Un mascaret est observé dans un certain nombre d'estuaires, durant la marée montante avec un grand marnage. On présente ici une étude expérimentale de propagation de mascaret sur une rugosité importante, en pratique un élément cylindrique. Dans l'écoulement initialement permanent, la rugosité générait un sillage, de dimensions comparables à celles reportées dans la littérature. Durant le passage du mascaret, la présence de la rugosité cylindrique modifiait le champs de vitesses et des contraintes de Reynolds. Les résultats indiquaient une augmentation des contraintes de cisaillement, et donc des risques d'érosion, autour de la rugosité, dans un périmètre correspondant à un rayon de deux diamètres de rugosité,

Mots-clés: Mascarets, Grande rugosité, Modèlisation physique, Mélange turbulent instationnaire 


\section{INTRODUCTION}

A tidal bore is a discontinuity of the water depth, and a hydrodynamic shock, surging upstream in shallow-water bays and estuaries during the flood tide under spring tidal conditions, when the tidal range exceeds 4-6 $\mathrm{m}$ and the flood tide confined to the narrow funnelled estuary (Tricker 1965, Lighthill 1978, Chanson 2011a). It is estimated worldwide that over 400-450 estuaries are affected by a tidal bore. For example, in the Bay of Fundy, several rivers are subject to a tidal bore process, including the Petitcodiac, Hebert, Cornwallis, Maccan and Salmon Rivers. Figure 1 presents photographs of tidal bores propagating upstream. A tidal bore has a significant impact on the environmental system and the ecology of the river mouth (Rulifson and Tull 1999, Locke et al. 2003, Ezer et al. 2008). Tidal bores can also be dangerous, impacting adversely on man-made structures (Fig. 1) and endangering lives. In recent years, the Hoogly River bore (India) gained in strength because of the completion of upstream dams, and the tidal bore destroyed several bridge structures. The impact of a tidal bore on bridges and bridge piers was rarely documented, although some studies were conducted on the impact of the G15 Shenhai Expressway and G15W Changtai Expressway bridges over the Hangzhou Bay and Qiantang River mouth (China) (Lu et al. 2009, Xu and Liang 2010). Another example is the 15th century Pont Aubaud bridge on the Sélune River (France) (Chanson 2011b). Further research was conducted on the impact of tidal bores on groyne structures (Xu et al. 2016). A related literature is the impact of tsunami bores on man-made structures, include bridge piers (e.g. Arnason et al. 2009, Mori et al. 2013, St-Germain et al. 2014).

A tidal bore is a positive surge, also called compression wave or translating hydraulic jump (Henderson 1966, Liggett 1994). The shape of the bore front is characterised by its Froude number $\mathrm{Fr}_{1}$, whose expression may be derived based upon momentum considerations for an irregular channel cross-section:

[1] $\mathrm{Fr}_{1}=\frac{\mathrm{V}_{1}+\mathrm{U}}{\sqrt{\mathrm{g} \times \frac{\mathrm{A}_{1}}{\mathrm{~B}_{1}}}}$

where $\mathrm{V}_{1}$ is the initial flow velocity positive downstream, $\mathrm{U}$ is the bore celerity positive upstream, $g$ is the gravity acceleration, $A_{1}$ is the initial flow cross-section area and $B_{1}$ is the initial free-surface width (Leng and Chanson 2015). For $\mathrm{Fr}_{1}<1.3$ to1.4, the bore is undular: its 
front is followed by a train of quasi-periodic free-surface undulations (Peregrine 1966, Treske 1994). For larger Froude numbers, the bore has a marked roller (Hornung et al. 1995, Docherty and Chanson 2012) as illustrated in Figures $1 \mathrm{~b}$ and 1c.

A major challenge with any field investigation is the lack of control and of repeatability of each bore event (e.g. Simpson et al. 2004, Xie and Pan 2013, Keevil et al. 2015). In contrast, laboratory observations allow to conduct carefully-controlled experiments and to investigate systematically all relevant hydrodynamic parameters. It is the purpose of this study to investigate thoroughly the propagation of tidal bores over a large cylindrical roughness element, representative of a damaged bridge pier foundation. Herein new measurements were conducted in a relatively large-size facility $(\mathrm{L}=15 \mathrm{~m}, \mathrm{~B}=0.5 \mathrm{~m})$ and free-surface elevation and velocity were recorded simultaneously. The turbulence and turbulent mixing generated by the passage of the tidal bore were carefully documented under controlled flow conditions. The experimental results showed the impact of the large element on the steady and unsteady turbulent shear stresses in the close vicinity of the element.

\section{PHYSICAL MODELLING AND EXPERIMENTAL SETUP}

\section{Presentation}

Considering a tidal bore propagating upstream past a large roughness element (Fig. 2), a dimensional analysis gives a series of dimensionless relationships between the instantaneous flow properties at a location $(\mathrm{x}, \mathrm{y}, \mathrm{z})$ at a time $\mathrm{t}$ and the boundary conditions, inflow properties and fluid properties. For a large cylindrical element located on the centreline of a smooth horizontal rectangular channel, it yields:

$$
\begin{aligned}
& \frac{\mathrm{d}}{\mathrm{d}_{1}}, \frac{\overrightarrow{\mathrm{V}}}{\mathrm{V}_{1}}, \frac{\mathrm{P}}{\rho \times \mathrm{g} \times \mathrm{d}_{1}}, \frac{\|\tau\|}{\rho \times \mathrm{V}_{1}^{2}}= \\
& \mathrm{F}\left(\frac{\mathrm{x}-\mathrm{x}_{\mathrm{o}}}{\mathrm{d}_{1}}, \frac{\mathrm{y}}{\mathrm{d}_{1}}, \frac{\mathrm{z}}{\mathrm{d}_{1}}, \mathrm{t} \times \sqrt{\frac{\mathrm{g}}{\mathrm{d}_{1}}}, \frac{\mathrm{D}}{\mathrm{d}_{1}}, \frac{\mathrm{H}}{\mathrm{d}_{1}}, \frac{\mathrm{V}_{1}+\mathrm{U}}{\sqrt{\mathrm{g} \times \mathrm{d}_{1}}}, \rho \times \frac{\left(\mathrm{V}_{1}+\mathrm{U}\right) \times \mathrm{d}_{1}}{\mu}, \frac{\mathrm{g} \times \mu^{4}}{\rho \times \sigma^{3}}, \frac{\mathrm{x}_{\mathrm{o}}}{\mathrm{d}_{1}}, \frac{\mathrm{B}}{\mathrm{d}_{1}}, \ldots\right)
\end{aligned}
$$

where $\mathrm{d}$ is the instantaneous water depth, $\overrightarrow{\mathrm{V}}$ is the instantaneous velocity vector of components $V_{x}, V_{y}, V_{z}$, respectively the longitudinal, transverse and vertical velocity components, $d_{1}$ is the initial flow depth, $\mathrm{P}$ is the instantaneous pressure, $\|\tau\|$ is the instantaneous Reynolds stress 
tensor, $\mathrm{x}$ is the coordinate in the flow direction, $\mathrm{x}_{\mathrm{o}}$ is the longitudinal location of the large cylindrical roughness element centre, $\mathrm{D}$ and $\mathrm{H}$ are respectively the diameter and height of the large cylindrical element, $\mathrm{y}$ is the horizontal transverse coordinate measured from the channel centreline, $\mathrm{z}$ is the vertical coordinate measured from channel bed, $\mathrm{t}$ is the time, $\mu$ is the water dynamic viscosity, $\sigma$ is the surface tension between air and water and B is the channel width. Equation [2] expresses the instantaneous turbulent flow properties at a point and time as functions of the tidal bore properties, initial flow properties (subscript 1), channel geometry and fluid properties. The seventh, eighth and ninth terms are the tidal bore Froude number $\mathrm{Fr}_{1}$, Reynolds number Re and the Morton number Mo, the latter being a function of fluid properties and gravity constant only. In addition, the biochemical properties of the water may be considered particularly in natural estuarine systems, as well as the sediment characteristics.

In tidal bores, a Froude similitude is derived theoretically (Henderson 1966, Lighthill 1978, Leng and Chanson 2015). That is, the model and prototype Froude numbers must be equal. In the present study, the same fluids (air and water) were used in model and prototype, and this added a dimensional constraint: i.e., the Morton number was an invariant. Both Froude and Morton similitudes were adopted herein following Hornung et al. (1995) and Docherty and Chanson (2012), although the Reynolds number was underestimated. The present study focused on experiments performed under controlled flow conditions in a relatively large size facility selected to minimise potential viscous scaling effects: e.g., using relatively large initial depths and velocities, and Reynolds numbers (Table 1).

\section{Experimental channel and instrumentation}

New experiments were conducted in a $15 \mathrm{~m}$ long $0.5 \mathrm{~m}$ wide horizontal channel. The flume was made of smooth PVC bed and glass walls. The initially steady flow was supplied by an upstream water tank, $2.0 \mathrm{~m}$ long and $1.25 \mathrm{~m}$ wide, equipped with baffles and two rows of flow straighteners, leading the water to the channel through a smooth three-dimensional convergent. The initial flow depth could be controlled by a radial gate located next to the downstream end of the channel: $\mathrm{x}=14.75 \mathrm{~m}$, where $\mathrm{x}$ is the longitudinal distance from the glass-walled flume's upstream end. The tidal bore was generated by the rapid closure of a Tainter gate located at $\mathrm{x}=$ 
$14.10 \mathrm{~m}$ just upstream of the radial gate (Fig. 2). The Tainter gate closure time was less than $0.15 \mathrm{~s}$ to $0.2 \mathrm{~s}$ and the gate closure time had no impact on the upstream bore propagation.

The water discharge was measured with a Venturi meter with an accuracy of $2 \%$. In steady flows, the water depth was measured using pointer gauges with an error of $\pm 0.5 \mathrm{~mm}$. The unsteady flow depth was measured with a series of acoustic displacement meters Microsonic ${ }^{\mathrm{TM}}$ Mic $+25 / \mathrm{IU} / \mathrm{TC}$ located at several longitudinal distances above the channel centreline: $\mathrm{x}=6.1 \mathrm{~m}$, $7.1 \mathrm{~m}, 8.1 \mathrm{~m}, 9.1 \mathrm{~m}, 13.85 \mathrm{~m}, 14.15 \mathrm{~m}$ with an accuracy of $0.18 \mathrm{~mm}$ (Microsonic 2004). The last sensor $(\mathrm{x}=14.15 \mathrm{~m})$ was located immediately downstream of the Tainter gate as sketched in Figure 2. The instantaneous velocity measurements were performed using an acoustic

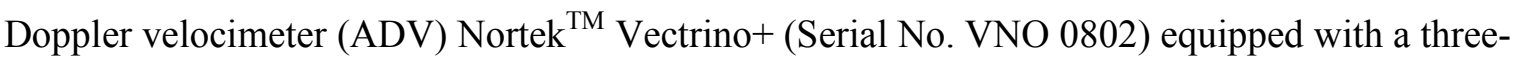
dimensional side-looking head. The ADV head is seen in Figure 3. The error on the velocity data was $1 \%$ of the velocity range $( \pm 1 \mathrm{~m} / \mathrm{s}$ herein): that is $\pm 0.01 \mathrm{~m} / \mathrm{s}$ (Nortek 2009). The acoustic displacement meters and ADV were synchronised within $1 \mathrm{~ms}$, and sampled simultaneously at $200 \mathrm{~Hz}$. The vertical translation of ADV system was controlled by a fine adjustment traverse connected to a Mitutoyo ${ }^{\mathrm{TM}}$ digimatic unit. The error on the vertical position was less than $0.025 \mathrm{~mm}$. The horizontal (longitudinal and transverse) positions of the ADV was recorded within $0.5 \mathrm{~mm}$.

\section{Channel bed configuration and initial flow conditions}

Two channel bed configurations were tested. Configuration A was the original smooth PVC bed. In Configuration B, a large roughness element was fixed to the PVC bed, with its center on the channel centreline $(y=0)$ at $x_{0}=7.1 \mathrm{~m}$ (Figures 2 and 3). The cylindrical element was manufactured out of PVC, with an accuracy of $\pm 0.1 \mathrm{~mm}$. Its diameter was: $\mathrm{D}=0.060 \mathrm{~m}$ and its height: $\mathrm{H}=0.020 \mathrm{~m}$.

The presence of the large cylindrical roughness element on the channel bed had an influence on the initially steady flow field. Its effect was investigated in terms of the vertical distributions of time-averaged longitudinal velocity and standard deviations of the three velocity components to establish the region of influence of the roughness element. The measurements were performed upstream of, directly at or above the element and downstream of the roughness element. Overall 
the results showed that the large roughness element had little impact on the flow upstream of and at the element, except in its immediate vicinity. Downstream of the element, a wake region was observed. Within the experimental flow conditions (Table 1), the wake region extended up to a distance $\left(\mathrm{x}-\mathrm{x}_{\mathrm{O}}\right) / \mathrm{D}<20$, with a vertical extent $\mathrm{z} / \mathrm{H}<4$ where $\mathrm{H}$ is the height of the element, and a transverse extent $-4<y / D<4$. Typical results are illustrated in Figure 4 , where $x-x_{0}$ is the longitudinal distance from the large element centre. In Figure 4, the downstream half of the large element is shown with a thick solid black line. Altogether the extents of the wake region was comparable with literature results for a short cylindrical element (Raupach 1992, Sutton and McKenna-Neuman 2008).

\section{Experimental flow conditions}

This study focused on fully-developed positive surges for which the mean properties became independent of time and space, thus independent of the generation process. Detailed velocity measurements were performed at several longitudinal locations $\mathrm{x}$ upstream of, above and downstream of the cylindrical element on the channel centreline, as well as at several transverse locations $\mathrm{y}$. The initially steady flow data indicated that the flow was partially developed at $\mathrm{x}=$ $6.1 \mathrm{~m}$ upstream of the element and the dimensionless boundary layer thickness $\delta / \mathrm{d}_{1}$ ranged between 0.5 and 0.6 depending upon the initial flow conditions.

Three water discharges were tested: $\mathrm{Q}=0.039 \mathrm{~m}^{3} / \mathrm{s}, 0.051 \mathrm{~m}^{3} / \mathrm{s}$ and $0.061 \mathrm{~m}^{3} / \mathrm{s}$ (Table 1$)$. For each experiment, the tidal bore was generated by the rapid closure of the Tainter gate and the bore propagated upstream as sketched in Figure 2 and illustrated in Figure 3. The radial gate was fully opened for the breaking bore experiments; it was partially closed to raise the initial water depth $\mathrm{d}_{1}$ during the undular bore experiment.

Several experimental series were performed. Series 1 included steady flow velocity measurements upstream and downstream of the large roughness element, to document the effects of the element on the initially steady flow and the extent the wake region downstream of the cylindrical element. At each location, the velocity was sampled at $200 \mathrm{~Hz}$ for $180 \mathrm{~s}$. Series 2 focused on free-surface measurements during the propagation of positive surge. Series 3 included a series of instantaneous velocity and free-surface elevation measurements during the 
propagation of tidal bore. Both instantaneous and ensemble-average experiments were performed. For each run, the instruments were started $60 \mathrm{~s}$ prior to gate closure. The sampling stopped when the bore front reached the upstream convergent structure. For each set of ensemble-average experiments, a total of 25 runs were repeated during experiments Series 2 and 3. The median free-surface elevations and velocity components were calculated from the total ensemble, as well as the fluctuating properties. Table 1 summarises the experimental flow conditions.

\section{FLOW PATTERNS}

Free-surface measurements under unsteady flow conditions were conducted for three breaking and one undular bore flow conditions (Table 1). The rapid gate closure generated a bore propagating upstream against the initially steady flow. Figure 3 shows a typical sequence of photographs taken during the propagation of a breaking bore. In Figure 3, the scale is provided by the cylindrical element size $(\mathrm{D}=0.06 \mathrm{~m})$. The bore passage was characterised by a rapid rise in free-surface elevation. For $\mathrm{Fr}_{1}<1.3$, the bore free-surface was smooth and the first wave crest was followed by a train of secondary undulations. For larger Froude numbers, a marked roller was observed associated with large scale turbulence and air bubble entrainment (Fig. 3). The free-surface properties were analysed based upon the ensemble-average free-surface data. Typical results are presented in Figures 5 and 6, in terms of the ratio of conjugate depths and maximum free-surface elevation. In Figure 5, the data compare well with the Bélanger equation as well as past experimental data in horizontal rectangular channels with both smooth and rough inverts. Figure 6 presents the maximum free-surface elevation, and the data are compared with the apparition of slight breaking at the first wave crest: $d_{2} / d_{1}-1=0.4$ (Chanson 2010a), and an upper limit corresponding well to the criterion for solitary wave breaking (Peregrine 1966). Both present data and past results are in agreement, showing an upper limit corresponding well to the criterion for solitary wave breaking (Peregrine 1966).

The propagation of tidal bores was associated with large instantaneous free-surface fluctuations during the bore passage. This is illustrated in Figure 7, showing the time variations of the ensemble-averaged water depth and difference between third and first quartiles $\left(\mathrm{d}_{75}-\mathrm{d}_{25}\right)$ during 
the generation and upstream propagation of a breaking bore. In Figure 7, the time $t$ is measured from the Tainter gate closure, the median depth data are shown with thick lines and the freesurface fluctuations are plotted in thin lines. For a Gaussian distribution of the data about the ensemble-average, the difference between third and first quartiles $\left(d_{75}-d_{25}\right)$ would be equal to 1.3 times the standard deviation. The experimental results indicated further maximum freesurface fluctuations shortly after the bore leading edge, as reported by Leng and Chanson (2016).

Both visual observations and instantaneous and ensemble-averaged acoustic displacement meter data showed the negligible impact of the large roughness element on the free-surface characteristics. For example, the breaking bore data reported in Figures 5 and 6 show no distinctive difference between the two bed configurations.

\section{VELOCITY OBSERVATIONS}

The instantaneous velocity measurements showed a sudden deceleration associated with the passage of the tidal bore for all experiments. This rapid deceleration phase was followed by a transient recirculation, previously documented in earlier studies (Docherty and Chanson 2012, Khezri and Chanson 2012, Leng and Chanson 2016). The passage of the tidal bore was linked to large fluctuations of the velocity components (data not shown). Typical experimental data are presented in Figures 8 and 9, showing the time variations of median longitudinal velocity (Fig. 8 ) and instantaneous longitudinal velocity fluctuations $\left(\mathrm{V}_{75}-\mathrm{V}_{25}\right)$ (Figs. 8 and 9), In absence of large roughness element (e.g. Fig. 8a), the results were close to those of Leng and Chanson (2016) obtained with the same discharge per unit width and comparable Froude numbers. Herein the focus is on the impact of the large roughness element on the velocity field.

The effect of the large element was tested systematically in terms of the instantaneous and ensemble-averaged velocity components for the breaking bore at several transverse locations $\mathrm{y} / \mathrm{D}=0,0.5,0.75$ and 1 for each longitudinal location $\left(\mathrm{x}-\mathrm{x}_{\mathrm{o}}\right) / \mathrm{D}=-2,-1,0,+6$. A typical example is presented in Figure 8, showing the time-variations of ensemble-averaged longitudinal velocity component $\left(\mathrm{V}_{\mathrm{x}}-\mathrm{V}_{2}\right) /\left(\mathrm{V}_{1}-\mathrm{V}_{2}\right)$ on the channel centreline, where $\mathrm{V}_{2}$ is the 
conjugate flow velocity, all velocities are positive downstream and $t$ is the time since Tainter gate closure. The impact of the large element was most significant on the channel centreline for $-5<\left(\mathrm{x}-\mathrm{x}_{0}\right) / \mathrm{D}<+5$. First a longer transient recirculation was observed both upstream and downstream of the element. This is illustrated in Figure 8 where the blue arrow highlights the transient recirculation event, which was nearly twice as long in presence of the large element. Second the transient recirculation was characterised by stronger maximum velocity recirculation magnitudes: that is, almost $60 \%$ larger in presence of the roughness element.

Physically, and following the bore front, the advancing tidal bore encountered first the wake region downstream of the element, sketched in Figure 2. The interactions between the wake motion and the bore turbulence induced large velocity fluctuations next to the invert, in the initial wake region. Once the bore front passed the cylindrical element, a transient wake developed upstream of the large element. The transient wake was caused by the blockage effect induced by the large cylindrical element.

\section{TURBULENT REYNOLDS STRESSES}

The unsteady flow motion in tidal bores was characterised by large velocity fluctuations that must be associated with large turbulent stresses. The turbulent Reynolds stress equals the fluid density times by the cross-product of the turbulent velocity fluctuations, $\tau_{i j}=\rho \times V_{i} \times v_{j}$ where $\rho$ is the density of the fluid, $v$ is the velocity fluctuation and $i, j=x, y, z$. The instantaneous velocity fluctuation is calculated as: $\mathrm{v}=\mathrm{V}-\overline{\mathrm{V}}$, where $\mathrm{V}$ is the instantaneous velocity measurement and $\overline{\mathrm{V}}$ is a mean velocity. In steady flows, $\overline{\mathrm{V}}$ is the time-averaged velocity component. In a rapidly-varied unsteady flow, the experiments must be repeated several times and $\overline{\mathrm{V}}$ is the instantaneous ensemble-averaged velocity component (Bradshaw 1971). Herein the Reynolds stresses were calculated based upon the ensemble-average velocity data following Leng and Chanson (2016). Calculations were performed on velocity data with and without the presence of the large cylindrical element. Typical results are presented in Figure 10 in terms of the median shear stresses $\rho \times v_{x} \times v_{x}$ and $\rho \times v_{x} \times v_{y}$.

The experimental data showed that the propagation of the bore was associated with a marked increase in Reynolds stress magnitude during and immediately after the front passage, together 
with large and rapid fluctuations in turbulent stresses (Fig. 10). The maximum Reynolds stresses were typically observed after the bore arrival. The corresponding time lag was comparable with and without the roughness element, and close to the findings of Leng and Chanson (2016). Overall the patterns were observed for all Reynolds stress tensor components.

The presence of the cylindrical element was felt primarily upstream of the element and around the element. Lesser effect was observed downstream of the element. Upstream of the large roughness element, the bore front passage was followed by an increase in the mean normal and tangential stresses immediately upstream of the element at $\left(x-x_{0}\right) / D=-1$. Further upstream, only a slight increase in shear stresses was observed up to $\left(x-x_{0}\right) / D<-2$. Beside the element, that is $\left(\mathrm{x}-\mathrm{x}_{\mathrm{O}}\right)=0$, its presence impacted onto the shear stress data close to the bed at $\mathrm{y} / \mathrm{D}=0.75$ and 1 , with larger turbulent stress magnitudes. Beyond these locations, the effect of the cylindrical element was negligible.

The present results showed that a large roughness element may impact onto both steady and unsteady flow motions. During bore propagation, large shear stress levels were observed around the element, that might lead to enhanced scour and bed erosion, typically within two diameters from the element centre. The repetition of tidal bore events (e.g. twice a day during semi-diurnal spring tides) could yield the development of a large scour hole surrounding the cylindrical element, as observed during the construction of the G15W Changtai Expressway bridge across the Qiantang River, China (Ren and Luo 2010, Pan D.Z. 2013, Pers. Comm.).

\section{CONCLUSION}

In tidal bore affected estuaries and shallow-water bays, the upstream propagation of the bore induces significant mixing and high turbulence levels. The literature has been focused mostly on the propagation of tidal bores in flat bed channels, and the effects of large roughness elements were un-accounted for. Herein a physical study was performed to assess the impact of a large cylindrical roughness element on the upstream propagation of tidal bores, including the steady and unsteady turbulent shear stresses in the close vicinity of the element.

In the initially steady flow, the large and flat cylindrical element $(\mathrm{D} / \mathrm{H}=3)$ generated a wake region, extending up to 20 diameters downstream and $+/-4$ diameters in the transverse 
direction. The extents of the wake region were consistent with relevant steady flow literature. During the tidal bore propagation, the presence of the element had negligible effect on the freesurface properties. Its impact was felt in terms of the instantaneous velocity, with a longer transient recirculation both upstream and downstream of the element and larger maximum velocity recirculation magnitudes for $-5<\left(\mathrm{x}-\mathrm{x}_{0}\right) / \mathrm{D}<+5$. Larger velocity fluctuations were further recorded and the results were associated with larger turbulent shear stresses around the roughness element. The results suggested some enhanced turbulent stress levels, hence potential bed erosion, around the large element within two diameters from the element centre. The finding indicated the potential development of a large scour hole around the element in mobile bed channels, associated with the propagation of tidal bores.

Further investigations should be conducted using mobile bed materials, and could encompass both cylindrical element and cylindrical column. The latter would be representative of a bridge pier and an important application could be the prediction of scour hole development around a pier, for example in a tidal bore affected estuary.

\section{ACKNOWLEDGMENTS}

The authors thank Ms Xinqian (Sophia) Leng, The University of Queensland, for her input and advice. They acknowledge the helpful review comments. They further acknowledge the technical support of Jason Van Der Gevel and Stewart Matthews, The University of Queensland. The financial support through the Australian Research Council (Grant DP120100481) is acknowledged.

\section{REFERENCES}

Arnason, H., Petroff, C., and Yeh, H. 2009. Tsunami Bore Impingement onto a Vertical Column. Journal of Disaster Research, 4(6):392-403.

Bradshaw, P. 1971. An Introduction to Turbulence and its Measurement. Pergamon Press, Oxford, UK, The Commonwealth and International Library of Science and technology 
Engineering and Liberal Studies, Thermodynamics and Fluid Mechanics Division, 218 pages.

Chanson, H. 2010a. Unsteady Turbulence in Tidal Bores: Effects of Bed Roughness. Journal of Waterway, Port, Coastal, and Ocean Engineering, ASCE, 136(5):247-256. DOI: 10.1061/(ASCE)WW.1943-5460.0000048.

Chanson, H. 2010b. Undular Tidal Bores: Basic Theory and Free-surface Characteristics. Journal of Hydraulic Engineering, ASCE, 136(11):940-944. DOI: 10.1061/(ASCE)HY.19437900.0000264 .

Chanson, H. 2011a. Tidal Bores, Aegir, Eagre, Mascaret, Pororoca: Theory and Observations. World Scientific, Singapore, 220 pages.

Chanson, H. 2011b. Undular Tidal Bores: Effect of Channel Constriction and Bridge Piers. Environmental Fluid Mechanics, 11(4):385-404 \& 4 videos. DOI: 10.1007/s10652-0109189-5.

Docherty, N.J., and Chanson, H. 2012. Physical Modelling of Unsteady Turbulence in Breaking Tidal Bores. Journal of Hydraulic Engineering, ASCE, 138(5):412-419. DOI: 10.1061/(ASCE)HY.1943-7900.0000542.

Ezer, T., Hobbss, R., and Oey, L.Y. 2008. On the Movement of Beluga Whales in Cook Inlet, Alaska. Oceanography, 21(4):186-195.

Favre, H. 1935. Etude Théorique et Expérimentale des Ondes de Translation dans les Canaux Découverts. Dunod, Paris, France (in French).

Henderson, F.M. 1966. Open Channel Flow. MacMillan Company, New York, USA.

Hornung, H.G., Willert, C., and Turner, S. 1995. The Flow Field Downstream of a Hydraulic Jump. Journal of Fluid Mechanics, 287:299-316.

Keevil, C.E., Chanson, H., and Reungoat, D. 2015. Fluid Flow and Sediment Entrainment in the Garonne River Bore and Tidal Bore Collision. Earth Surface Processes and Landforms, 40(12):1574-1586. DOI: 10.1002/esp.3735.

Khezri, N., and Chanson, H. 2012. Undular and Breaking Tidal Bores on Fixed and Movable Gravel Beds. Journal of Hydraulic Research, IAHR, 50(4):353-363. DOI: 10.1080/00221686.2012.686200. 
Koch, C., and Chanson, H. 2008. Turbulent Mixing beneath an Undular Bore Front. Journal of Coastal Research, 24(4):999-1007. DOI: 10.2112/06-0688.1.

Leng, X., and Chanson, H. 2015. Breaking Bore: Physical Observations of Roller Characteristics. Mechanics Research Communications, 65:24-29. DOI: 10.1016/j.mechrescom.2015.02.008.

Leng, X., and Chanson, H. 2016. Coupling between Free-surface Fluctuations, Velocity Fluctuations and Turbulent Reynolds Stresses during the Upstream Propagation of Positive Surges, Bores and Compression Waves. Environmental Fluid Mechanics, 16, 25 pages (In Print). DOI: $10.1007 / \mathrm{s} 10652-015-9438-8$.

Liggett, J.A. 1994. Fluid Mechanics. McGraw-Hill, New York, USA.

Lighthill, J. 1978. Waves in Fluids. Cambridge University Press, Cambridge, UK, 504 pages.

Locke, A., Hanson, J.M., Klassen, G.J., Richardson, S.M., and Aube, C.I. 2003. The damming of the Petitcodiac River: Species, populations, and habitats lost. Northeastern Naturalist, 10(1):39-54. DOI: $10.2307 / 3858671$.

Lu, H.Y. Pan, C.H., and Zeng, J. 2009. Numerical simulation and analysis for combinational effects of two bridges on the tidal bore in the Qiantang River. Proceedings of 5th International Conference on Asian and Pacific Coasts, Singapore, 3:325-333.

Microsonic 2004. Instruction manual mic+ Ultrasonic Sensors with one analogue output. Microsonic GmbH, Germany, 3 pages.

Mori, N., Cox, D.T., Yasuda T., and Mase, H. 2013. Overview of the 2011 Tohoku Earthquake Tsunami damage and relation with coastal protection along the Sanriku coast. Earthquake Spectra, 29(S1):S127-S143. DOI: 10.1193/1.4000118.

Nortek 2009. Vectrino Velocimeter User Guide. Nortek AS, Norway, 42 pages.

Peregrine, D.H. 1966. Calculations of the Development of an Undular Bore. Journal of Fluid Mechanics, 25:321-330.

Raupach, M.R. 1992. Drag and drag partition on rough surfaces. Boundary Layer Meteorol., 60:375-395. DOI: 10.1007/BF00155203. 
Ren, L.L, and Luo, C.Y. 2010. The monitor of Qiantangjiang strong tidal water velocity and scouring of river-spanning bridge in Jiashao. Shanxi Architecture, 36(18):305-306 (in Chinese).

Rulifson, R.A., and Tull, K.A. 1999. Striped Bass Spawning in a Tidal Bore River : the Shubenacadie Estuary, Atlantic Canada. Transactions American Fisheries Society, 128:613624.

Simpson, J.H., Fisher, N.R., and Wiles, P. 2004. Reynolds Stress and TKE Production in an Estuary with a Tidal Bore. Estuarine, Coastal and Shelf Science, 60(4):619-627.

St-Germain, P., Nistor, P., Townsend, R., and Shibayama, T. 2014. Smoothed-Particle Hydrodynamics Numerical Modeling of Structures Impacted by Tsunami Bores. Journal of Waterway, Port, Coastal, and Ocean Engineering, ASCE, 140(1):66-81. DOI: 10.1061/(ASCE)WW.1943-5460.0000225.

Sutton, S.L.F., and McKenna-Neuman, C. 2008. Variation in Bed Level Shear Stress on Surfaces Sheltered by Nonerodible Roughness Elements. Journal of Geophysical Research, Earth Surface, 113, paper F103016, 12 pages. DOI: 10.1029/2007JF000967.

Treske, A. 1994. Undular Bores (Favre-Waves) in Open Channels - Experimental Studies. Journal of Hydraulic Research, IAHR, 32(3):355-370.

Tricker, R.A.R. 1965. Bores, Breakers, Waves and Wakes. American Elsevier Publ. Co., New York, USA.

Xie, D.F., and Pan, C.H. 2013. A preliminary study of the turbulence features of the tidal bore in the Qiantang River, China. Journal of Hydrodynamics, 25(6):903-911. DOI: 10.1016/S1001-6058(13)60439-4.

Xu, Z., and Liang, B. 2010. Experimental Study on Local Scour of Jiubao Bridge Pier in Hangzhou. Zhejiang Hydrotechnics, 170(4):13-17 (in Chinese).

Xu, C.J., Yin, M., and Pan, X.D. 2016. Field Test and Numerical Simulation of Tidal Bore Pressures on Sheet-Pile Groin in Qiantang River. Marine Georesources \& Geotechnology, 34:303-312. DOI: 10.1080/1064119X.2014.954683. 


\section{LIST OF SYMBOLS}
A flow cross-section area $\left(\mathrm{m}^{2}\right)$;
$\mathrm{A}_{1} \quad$ initial cross-section area $\left(\mathrm{m}^{2}\right)$;
B free-surface width (m);
$\mathrm{B}_{1} \quad$ initial free-surface width (m);
D large roughness element diameter (m);
d water depth (m);
$\mathrm{d}_{1} \quad$ initial water depth (m);
$\mathrm{d}_{2} \quad$ conjugate water depth (m);
$\mathrm{d}_{\max } \quad$ maximum water depth (m) during tidal bore passage;
Fr Froude number;
$\mathrm{Fr}_{1} \quad$ tidal bore Froude number;
g gravity constant $\left(\mathrm{m} / \mathrm{s}^{2}\right)$ or acceleration of gravity;
$\mathrm{H} \quad$ large roughness element height (m);
L test section length (m);
Mo Morton number;
P pressure $(\mathrm{Pa})$;
Q water discharge $\left(\mathrm{m}^{3} / \mathrm{s}\right)$;
q water discharge per unit width $\left(\mathrm{m}^{2} \mathrm{~s}\right)$;
Re flow Reynolds number;
$\mathrm{t}$ time (s) since Tainter gate closure;
$\mathrm{U} \quad$ tidal bore celerity $(\mathrm{m} / \mathrm{s})$ positive upstream;
$\mathrm{V}_{1} \quad$ initial flow velocity $(\mathrm{m} / \mathrm{s})$;
$\mathrm{V}_{2} \quad$ conjugate flow velocity $(\mathrm{m} / \mathrm{s})$;
$\mathrm{V}_{\mathrm{x}} \quad$ longitudinal velocity component $(\mathrm{m} / \mathrm{s})$;
$\mathrm{V}_{\mathrm{y}} \quad$ transverse velocity component $(\mathrm{m} / \mathrm{s})$;
$\mathrm{V}_{\mathrm{z}} \quad$ vertical velocity component $(\mathrm{m} / \mathrm{s})$;
$\overline{\mathrm{V}} \quad$ mean velocity $(\mathrm{m} / \mathrm{s})$; in a steady flow, $\overline{\mathrm{V}}$ is the time-averaged velocity; in a rapidly- varied unsteady flow, $\overline{\mathrm{V}}$ is the instantaneous ensemble-averaged velocity; 


$\begin{array}{ll}\mathrm{v} & \text { velocity fluctuation }(\mathrm{m} / \mathrm{s}) ; \\ \mathrm{v}_{\mathrm{x}} & \text { longitudinal velocity fluctuation }(\mathrm{m} / \mathrm{s}) ; \\ \mathrm{v}_{\mathrm{y}} & \text { transverse velocity fluctuation }(\mathrm{m} / \mathrm{s}) ; \\ \mathrm{v}_{\mathrm{z}} & \text { vertical velocity fluctuation }(\mathrm{m} / \mathrm{s}) ; \\ \mathrm{x} & \text { longitudinal distance }(\mathrm{m}) ; \\ \mathrm{x}_{\mathrm{o}} & \text { longitudinal position }(\mathrm{m}) \text { of large roughness element centre; } \\ \mathrm{y} & \text { transverse distance }(\mathrm{m}) \text { from the channel centreline; } \\ \mathrm{z} & \text { vertical elevation distance }(\mathrm{m}) \text { measured from the channel invert; }\end{array}$

\section{Greek symbols}

$\mu \quad$ water viscosity (Pa.s);

$\rho \quad$ water density $\left(\mathrm{kg} / \mathrm{m}^{3}\right)$;

$\sigma \quad$ surface tension $(\mathrm{N} / \mathrm{m})$ between air and water;

$\tau \quad$ shear stress $(\mathrm{Pa})$;

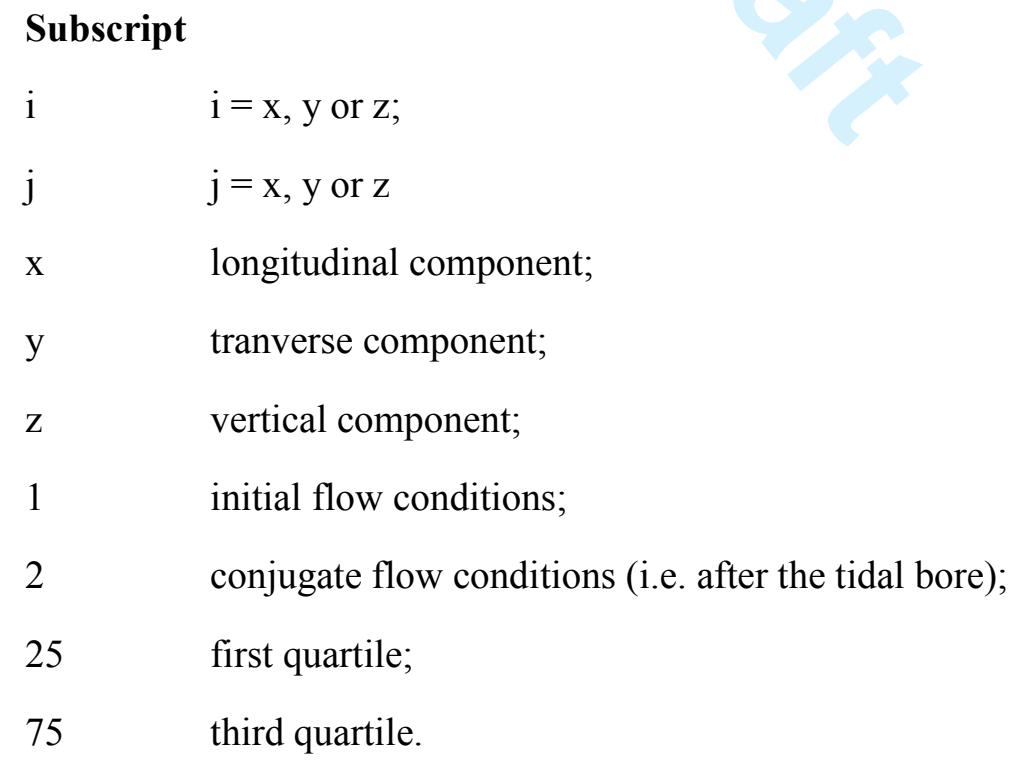


Table 1 - Experimental flow conditions

\begin{tabular}{|l|c|c|c|c|c|c|c|}
\hline \multirow{2}{*}{$\begin{array}{c}\text { Bed } \\
\text { configuration }\end{array}$} & $\mathrm{Q}\left(\mathrm{m}^{3} / \mathrm{s}\right)$ & $\mathrm{d}_{1}(\mathrm{~m})$ & $\begin{array}{c}\text { Radial gate } \\
\text { opening }(\mathrm{m})\end{array}$ & $\begin{array}{c}\text { Tainter gate } \\
\text { opening } \\
(\mathrm{m})\end{array}$ & $\mathrm{Fr}_{1}$ & $\mathrm{Re}$ & Surge type \\
\hline A - Smooth bed & 0.061 & 0.155 & N/A & 0.025 & 1.39 & $2.6 \times 10^{5}$ & Breaking \\
\hline B - Cylindrical & 0.039 & 0.200 & 0.060 & 0.010 & 1.11 & $2.9 \times 10^{5}$ & Undular \\
element & & 0.130 & N/A & 0.010 & 1.35 & $1.9 \times 10^{5}$ & Breaking \\
\cline { 2 - 9 } & 0.051 & 0.140 & N/A & 0.025 & 1.40 & $2.2 \times 10^{5}$ & Breaking \\
\cline { 2 - 9 } & 0.061 & 0.155 & N/A & 0.025 & 1.39 & $2.6 \times 10^{5}$ & Breaking \\
\hline
\end{tabular}

Notes: $\mathrm{d}_{1}$ : flow depth measured at $\mathrm{x}=6.1 \mathrm{~m} ; \mathrm{Fr}_{1}$ : bore Froude number; Re: bore Reynolds number; N/A: radial gate fully opened. 


\section{List of Figures}

Fig. 1 - Photographs of tidal bores impacting man-made structures

(a) Tidal bore of the Qiantang River, China impacting on an old seawall at Xinchang on 13 October 2014

(b) Tidal bore of the Qiantang River, China impacting a construction platform at Yanguan on 11 October 2014 - Bore propagation from left to right

(c) Tidal bore of the Qiantang River, China impacting a spur dyke between Yanguan and Laoyanchang on 11 October 2014 - Bore propagating from background to foreground, with the bore front impacting the spur dyke on the left

Fig. 2 - Definition sketch of the experimental channel

Fig. 3 - Photographic sequence of tidal bore propagation (from right to left) with $0.12 \mathrm{~s}$ between successive photographs (From left to right, top to bottom) - Flow conditions: $Q=0.061 \mathrm{~m}^{3} / \mathrm{s}, \mathrm{d}_{1}$ $=0.155 \mathrm{~m}$ at $\mathrm{x}=5.9 \mathrm{~m}, \mathrm{Fr}_{1}=1.39$, Tainter gate opening after closure: $\mathrm{h}=25 \mathrm{~mm}$, shutter speed: $1 / 400 \mathrm{~s}$

Fig. 4 - Dimensionless vertical distributions of time-averaged longitudinal velocity $\mathrm{V}_{\mathrm{x}}$ and standard deviation of longitudinal velocity $\mathrm{v}_{\mathrm{x}}{ }^{\prime}$ downstream of the cylindrical element in steady flow - Flow conditions: $\mathrm{Q}=0.038 \mathrm{~m}^{3} / \mathrm{s}, \mathrm{d}_{1}=0.130 \mathrm{~m}$ at $\mathrm{x}=5.9 \mathrm{~m}$, Flow direction from left to right - Note the large cylindrical element drawn with a thick solid line on bottom left

Fig. 5 - Ratio of conjugate depths in tidal bores propagating in a horizontal rectangular channel - Comparison between present ensemble-averaged data at $\mathrm{x}=7.1 \mathrm{~m}$ with and without large element and laboratory data on smooth invert (Favre 1935, Treske 1994, Chanson 2010a, Docherty and Chanson 2012, Leng and Chanson 2016) and rough invert (Chanson 2010a, Docherty and Chanson 2012) 
Fig. 6 - Dimensionless maximum water elevation $\left(\mathrm{d}_{\max }-\mathrm{d}_{1}\right) /\left(\mathrm{d}_{2}-\mathrm{d}_{1}\right)$ in tidal bores propagating in a horizontal rectangular channel - Comparison between present ensemble-averaged data at $\mathrm{x}=$ $7.1 \mathrm{~m}$ with and without large element, smooth invert data (Peregrine 1966, Koch and Chanson 2008, Chanson 2010a,2010b, Leng and Chanson 2016) and rough invert data (Chanson 2010a) and solitary wave breaking onset - Dashed line indicate the onset of breaking at the first wave crest

Fig. 7 - Time variations of median water depth $d_{\text {median }}$ and instantaneous free-surface fluctuations $\left(\mathrm{d}_{75}-\mathrm{d}_{25}\right)$ during the generation and upstream propagation of a breaking bore - Flow conditions: $\mathrm{Q}=0.061 \mathrm{~m}^{3} / \mathrm{s}, \mathrm{d}_{1}=0.155 \mathrm{~m}$ at $\mathrm{x}=5.9 \mathrm{~m}, \mathrm{Fr}_{1}=1.39, \mathrm{x}=7.1 \mathrm{~m}, \mathrm{y}=0$ (centreline data), no roughness element, Tainter gate opening after closure: $\mathrm{h}=25 \mathrm{~mm}$

Fig. 8 - Ensemble-averaged longitudinal velocity as a function of time: comparison between bed configuration A (no element) and bed configuration (with element) - Flow conditions: Q = $0.061 \mathrm{~m}^{3} / \mathrm{s}, \mathrm{d}_{1}=0.155 \mathrm{~m}$ at $\mathrm{x}=5.9 \mathrm{~m}, \mathrm{Fr}_{1}=1.39, \mathrm{z} / \mathrm{d}_{1}=0.04, \mathrm{y}=0$ (centreline), Tainter gate opening after closure: $\mathrm{h}=25 \mathrm{~mm}$ - Blue arrow marks transient recirculation

(a) Bed configuration A (no element)

(b) Bed configuration $\mathrm{B}:\left(\mathrm{x}-\mathrm{x}_{\mathrm{o}}\right) / \mathrm{D}=-2$ (i.e. upstream of large element)

(c) Bed configuration $\mathrm{B}:\left(\mathrm{x}-\mathrm{x}_{\mathrm{o}}\right) / \mathrm{D}=+2$ (i.e. downstream of large element)

Fig. 9 - Time variations of median water depth $d_{\text {median }}$, median longitudinal velocity $V_{x}$ and instantaneous longitudinal fluctuations $\left(\mathrm{V}_{75}-\mathrm{V}_{25}\right)$ during a breaking bore passage - Flow conditions: $\mathrm{Q}=0.061 \mathrm{~m}^{3} / \mathrm{s}, \mathrm{d}_{1}=0.155 \mathrm{~m}$ at $\mathrm{x}=5.9 \mathrm{~m}, \mathrm{Fr}_{1}=1.39,\left(\mathrm{x}-\mathrm{x}_{\mathrm{o}}\right) / \mathrm{D}=-2, \mathrm{y} / \mathrm{D}=-0.5, \mathrm{z} / \mathrm{d}_{1}$ $=0.13$, Tainter gate opening after closure: $\mathrm{h}=25 \mathrm{~mm}$

Fig. 10 - Time variations of ensemble-averaged Reynolds stresses $\mathrm{v}_{\mathrm{x}} \mathrm{v}_{\mathrm{x}}$ and $\mathrm{v}_{\mathrm{x}} \mathrm{v}_{\mathrm{y}}$ : comparison between bed configuration $A$ (no element) and bed configuration $B$ at $\left(x-x_{0}\right) / D=-2$ (upstream of large element) - Flow conditions: $\mathrm{Q}=0.061 \mathrm{~m}^{3} / \mathrm{s}, \mathrm{d}_{1}=0.155 \mathrm{~m}$ at $\mathrm{x}=5.9 \mathrm{~m}, \mathrm{Fr}_{1}=1.39, \mathrm{y}=$ 0 (centreline), Tainter gate opening after closure: $h=25 \mathrm{~mm}$ 

(a) Bed configuration A (no element), $\mathrm{z} / \mathrm{d}_{1}=0.04$
(b) Bed configuration $B$ at $\left(x-x_{0}\right) / D=-2, z / d_{1}=0.04$
(c) Bed configuration $\mathrm{B}$ at $\left(\mathrm{x}-\mathrm{x}_{\mathrm{o}}\right) / \mathrm{D}=-2, \mathrm{z} / \mathrm{d}_{1}=0.13$ 
$528 \quad$ (a)

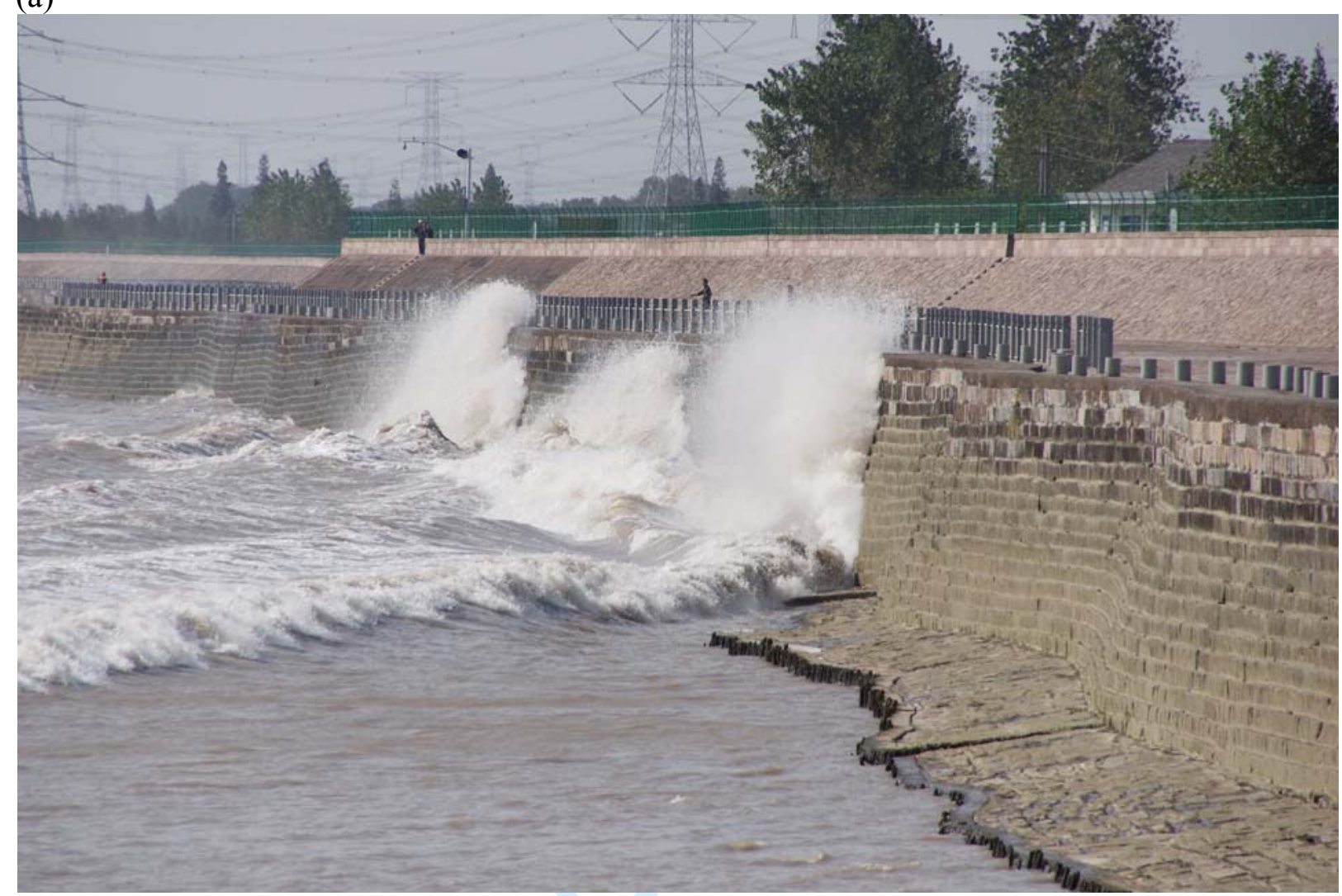


$531 \quad$ (b)

532

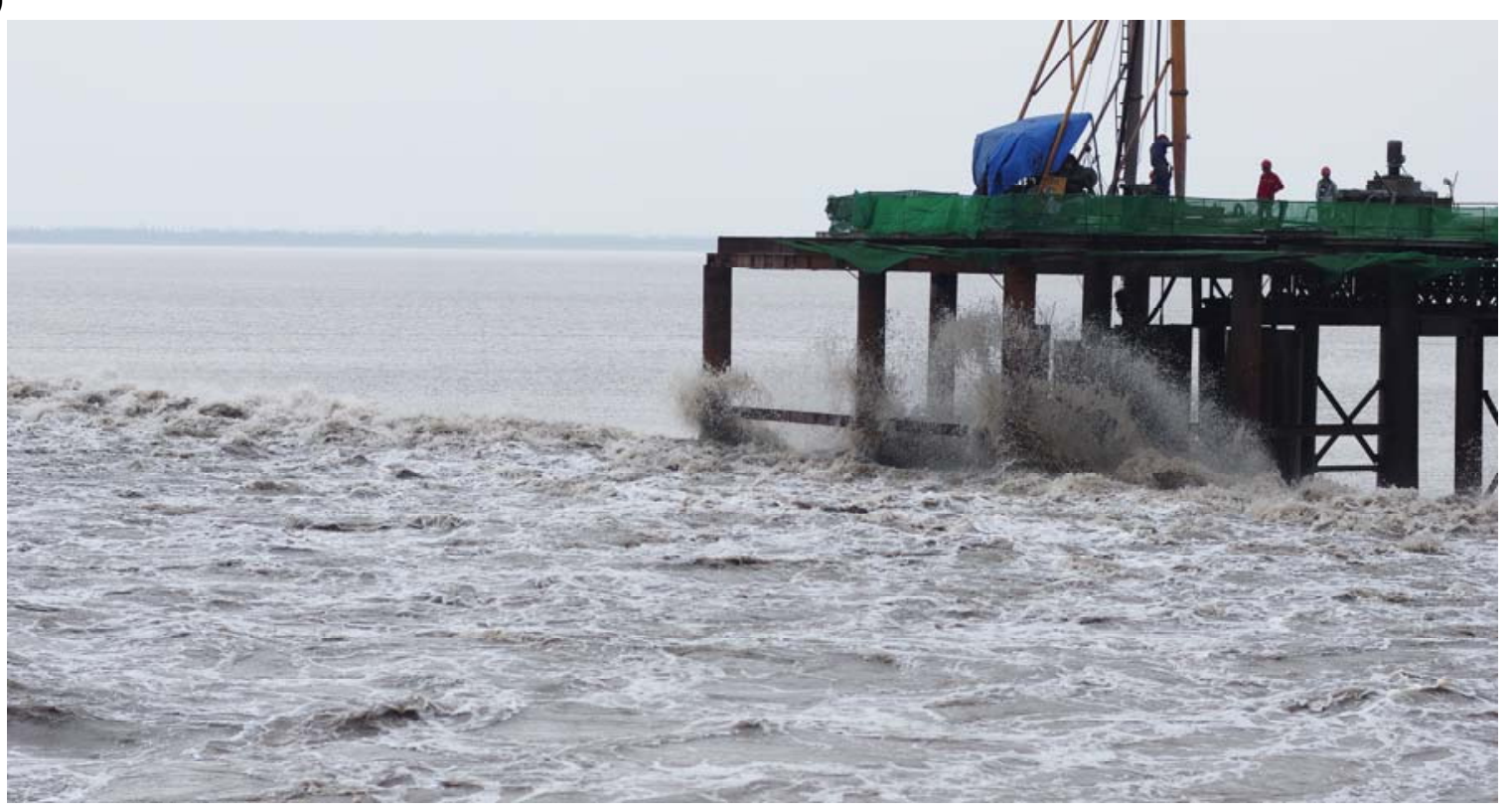

533 
534 (c)

535

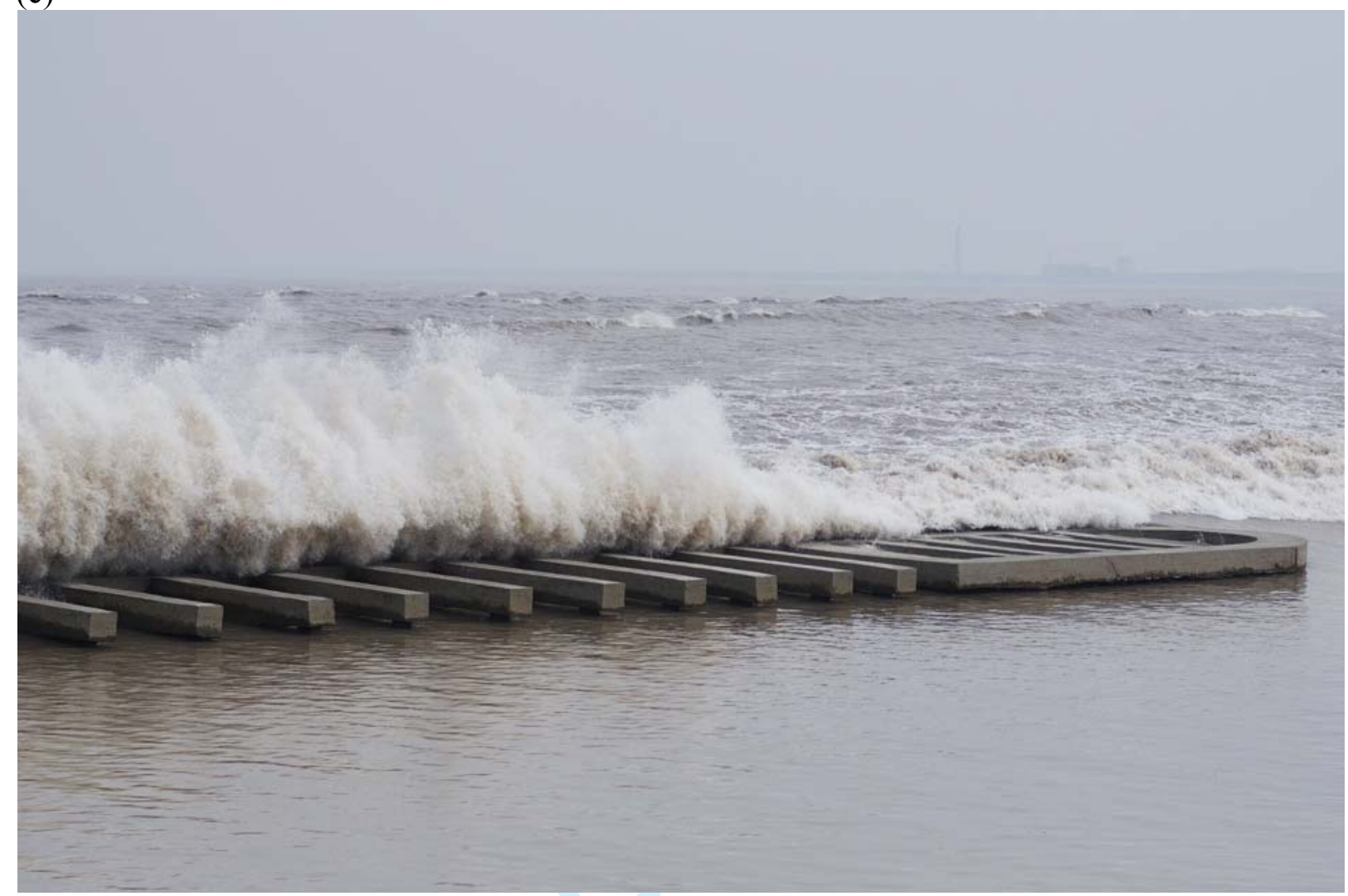

536

https://mc06.manuscriptcentral.com/cjce-pubs 


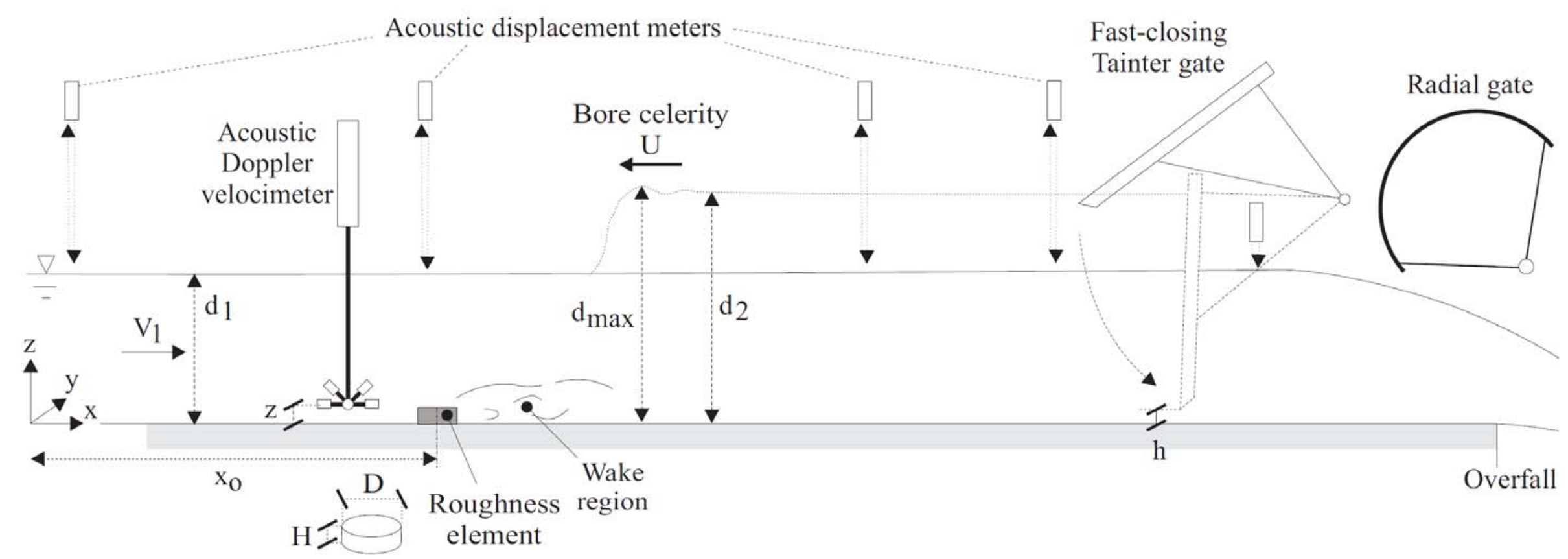



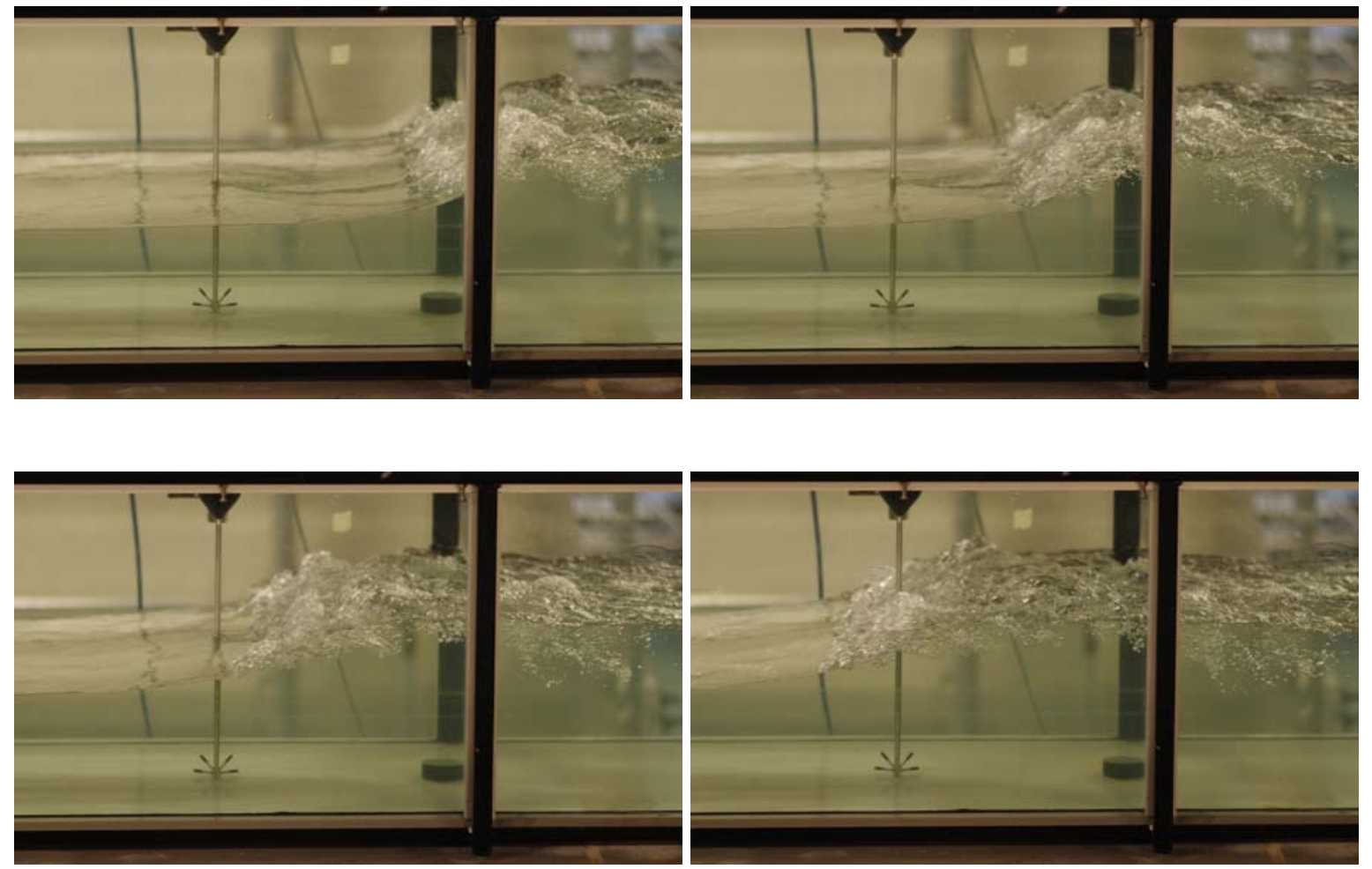


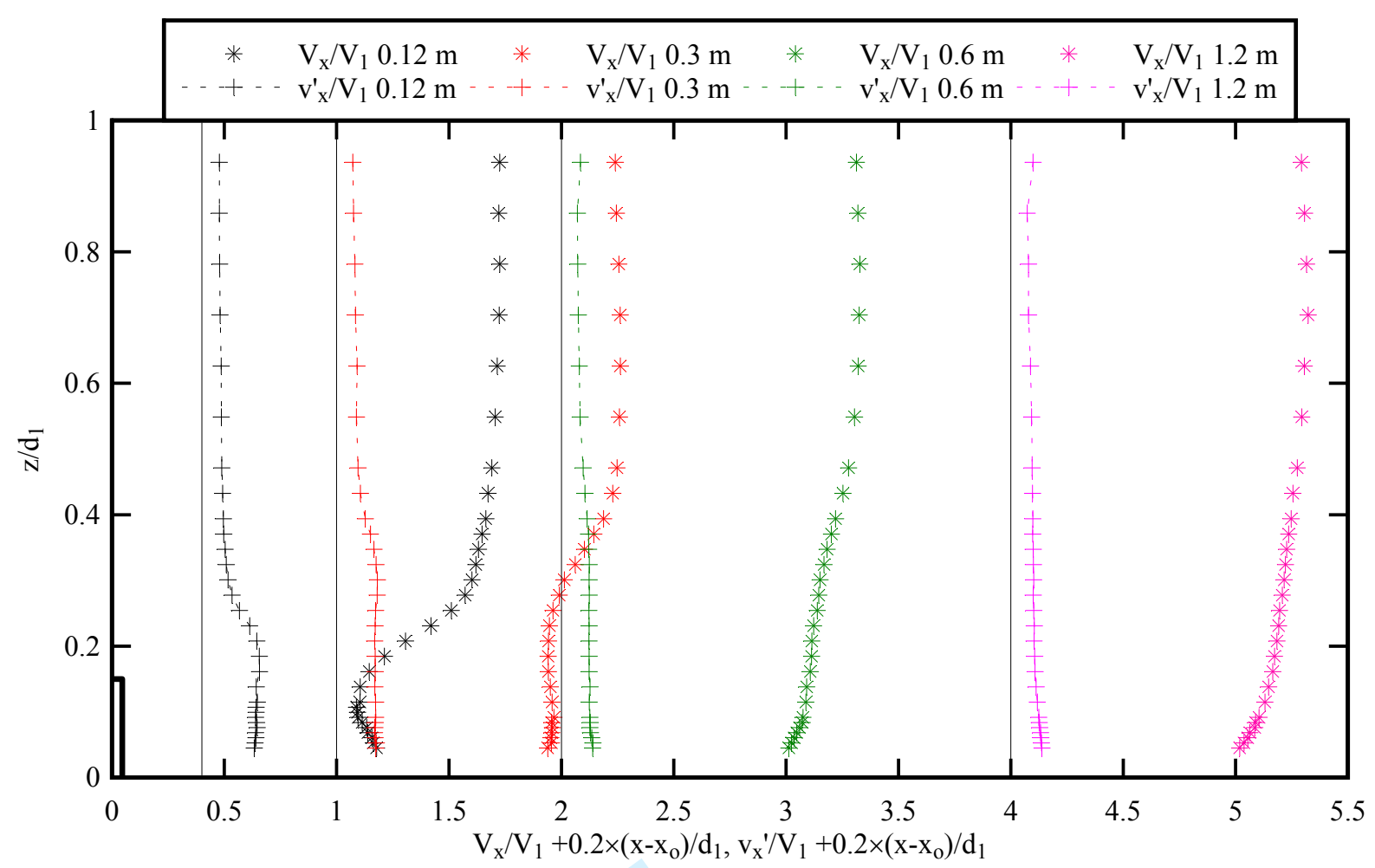




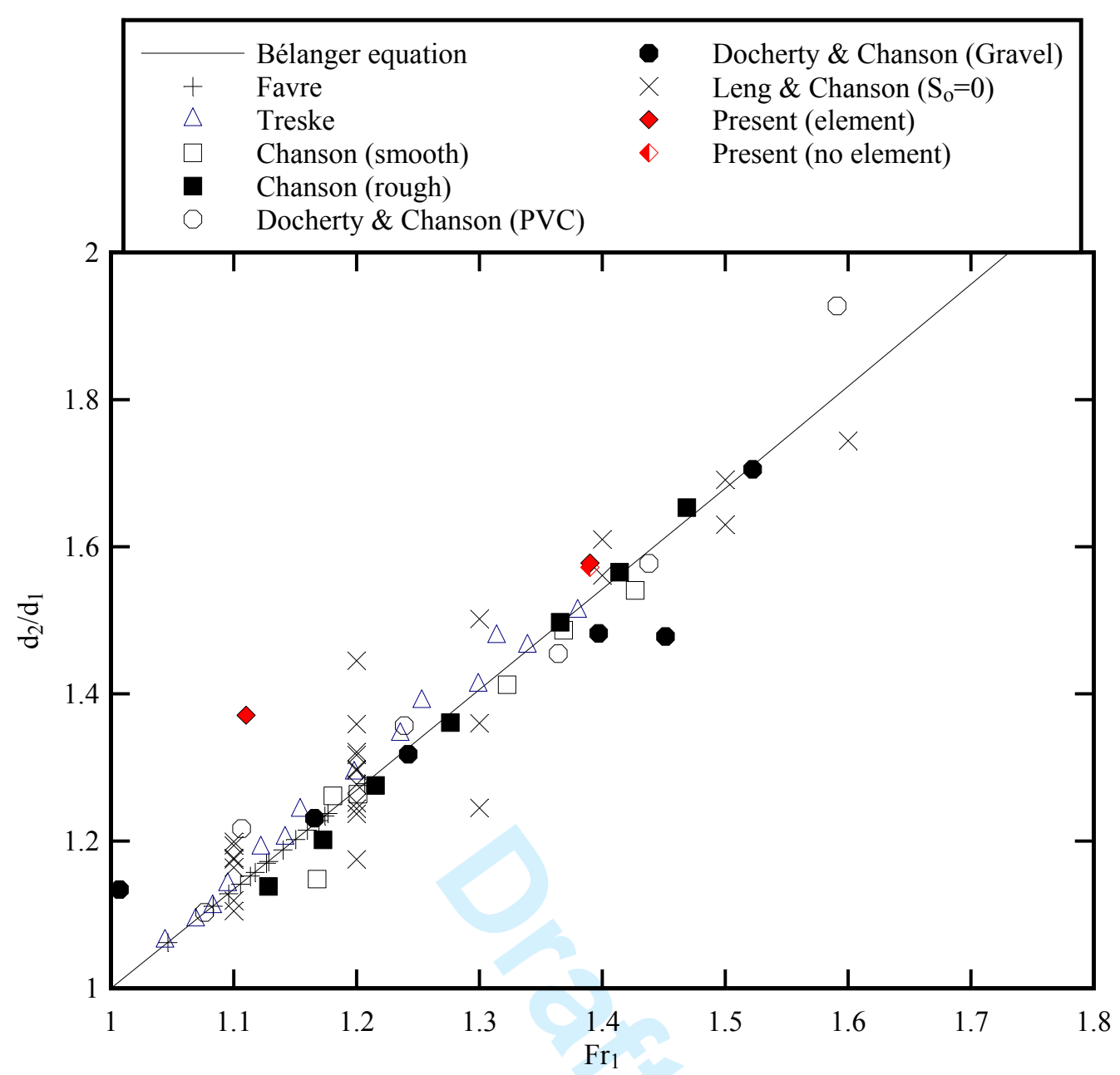




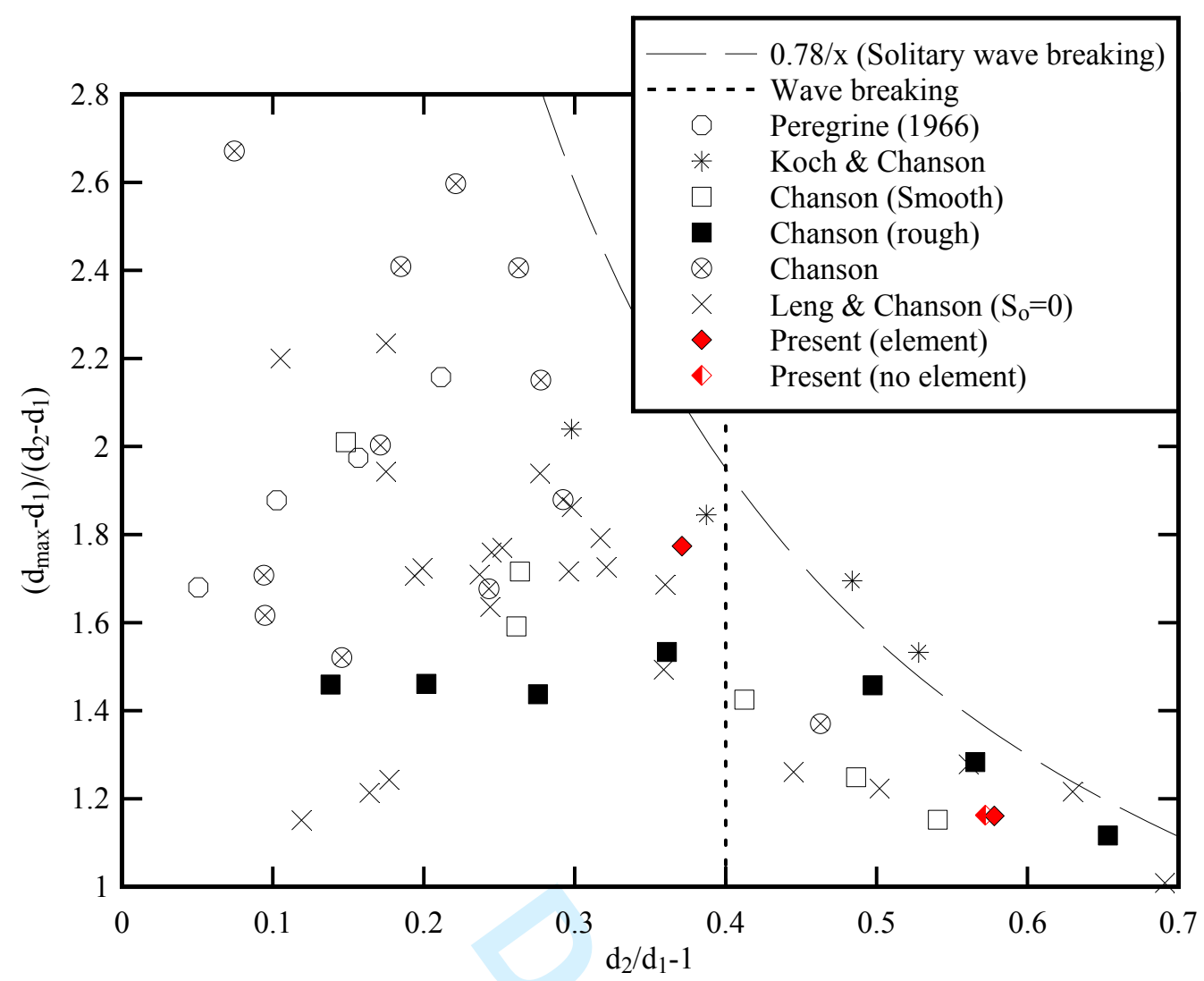




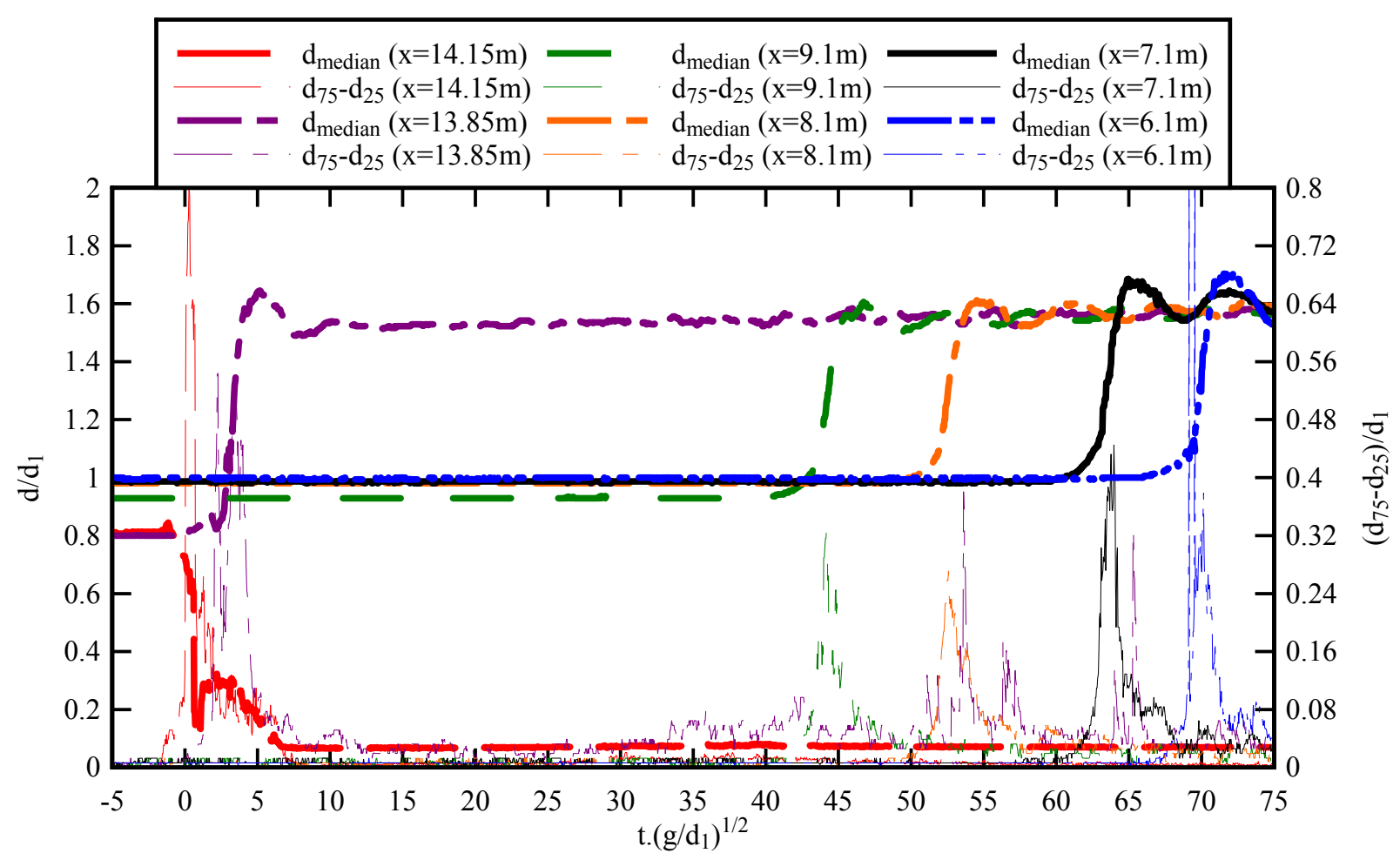


(a)

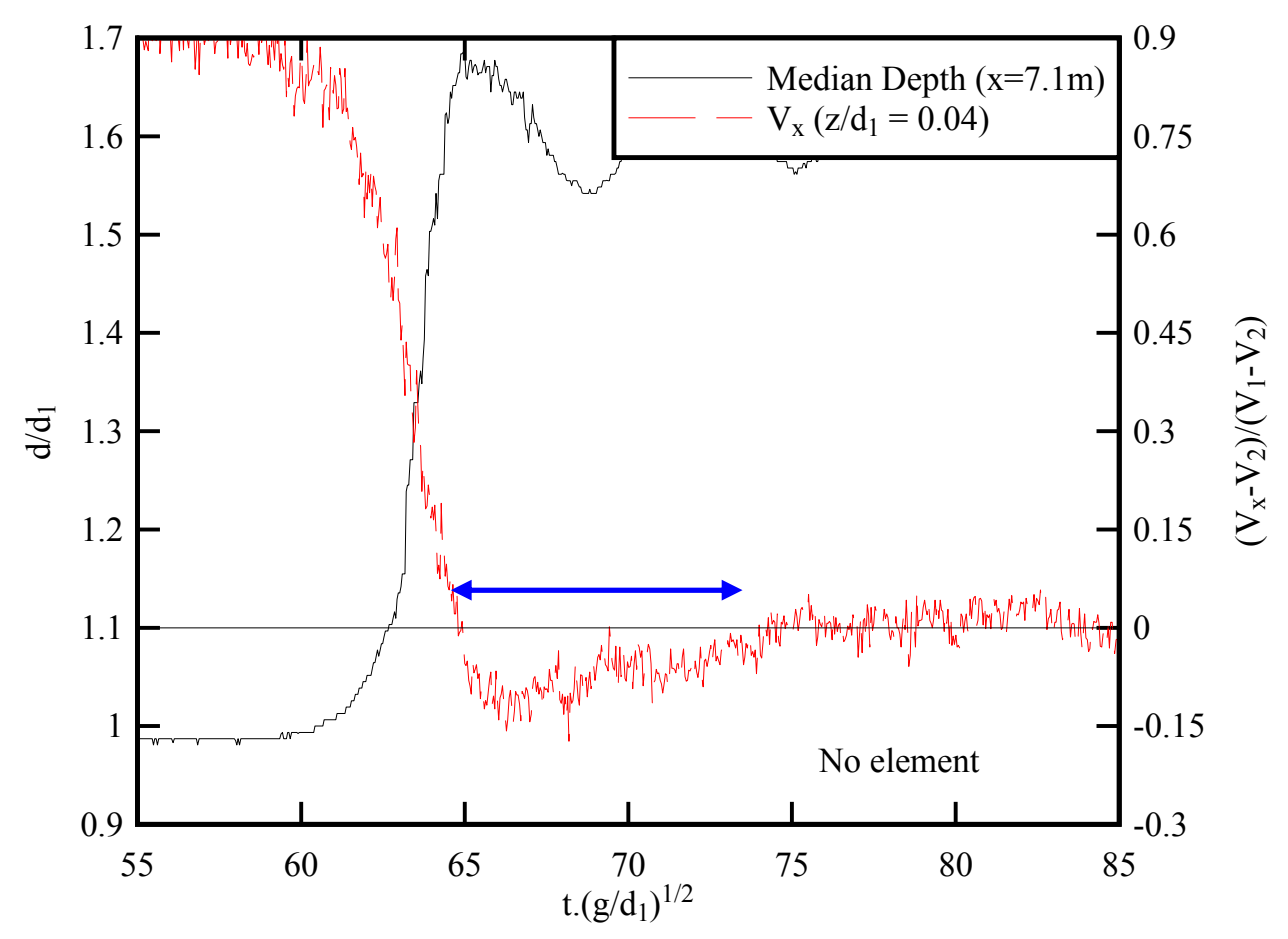


(b)

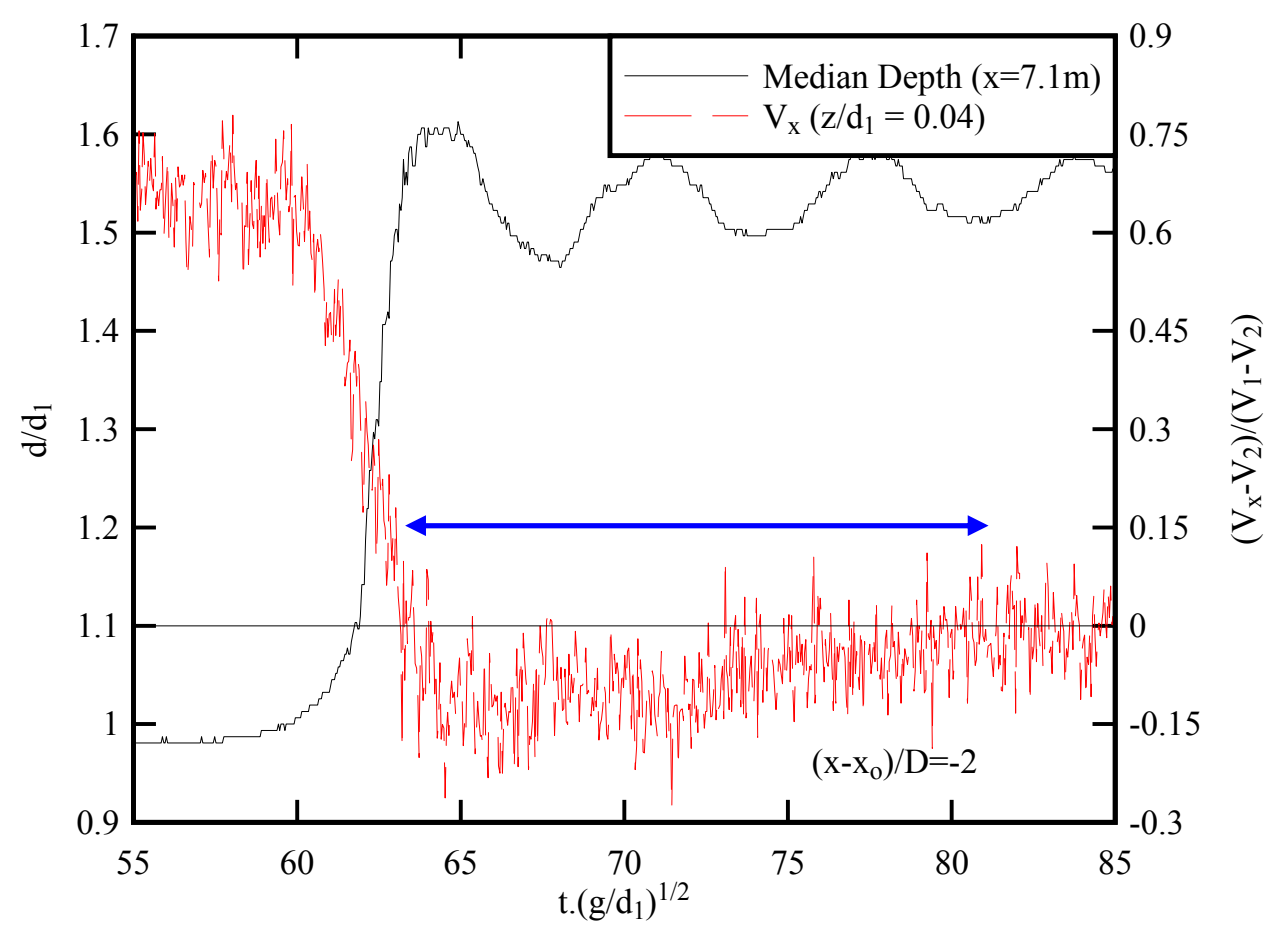


(c)

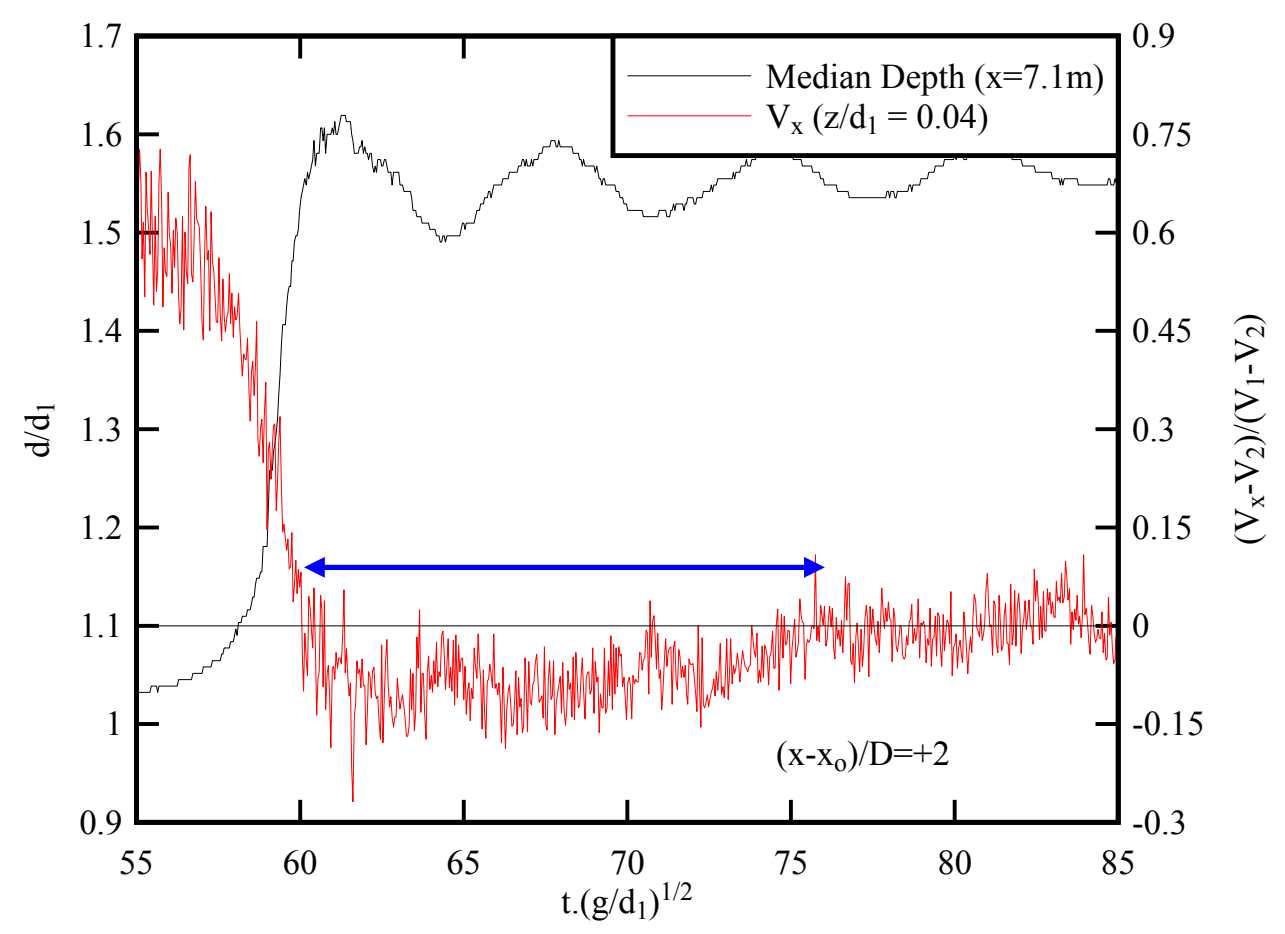




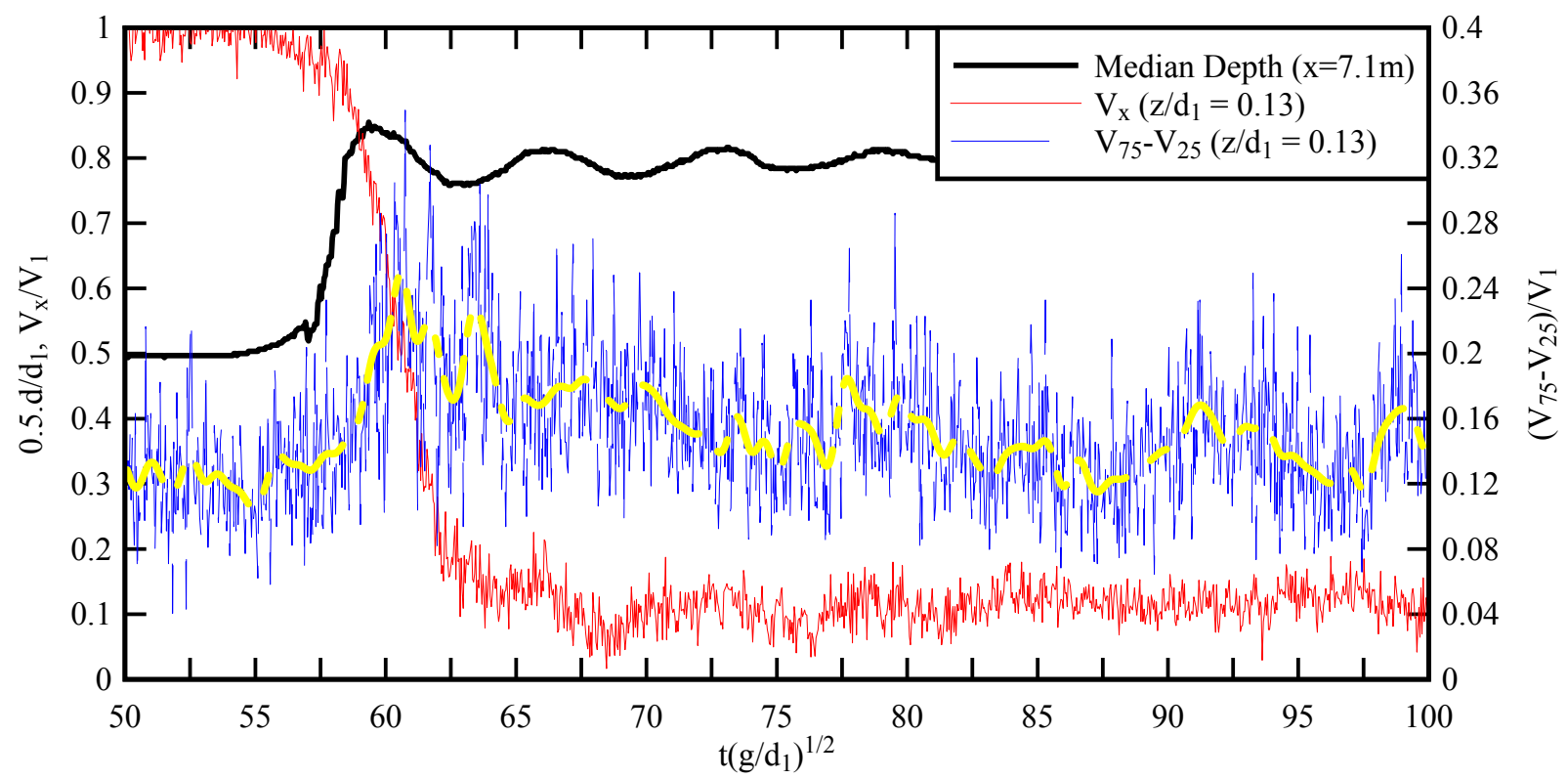


(a)

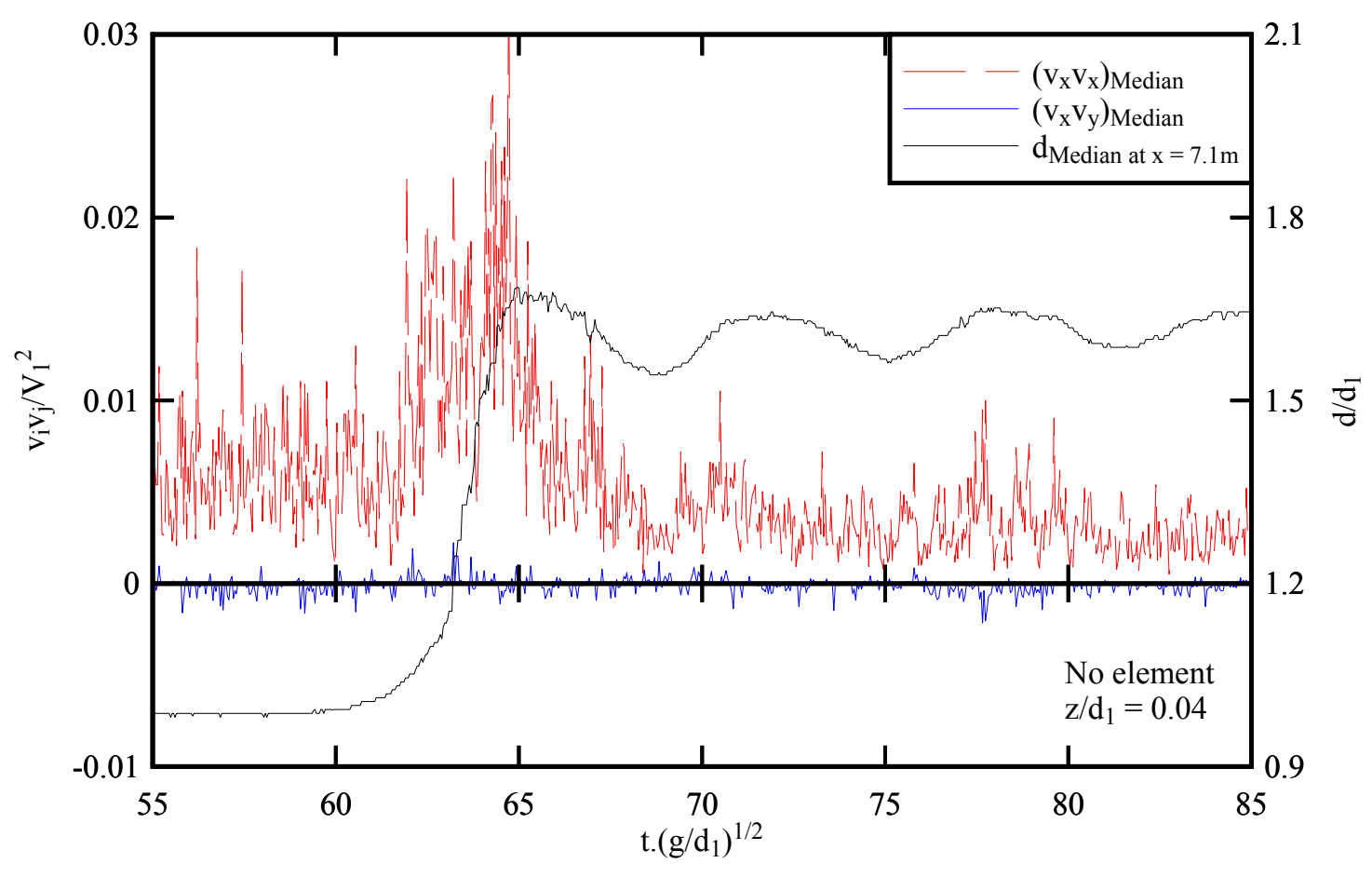


(b)

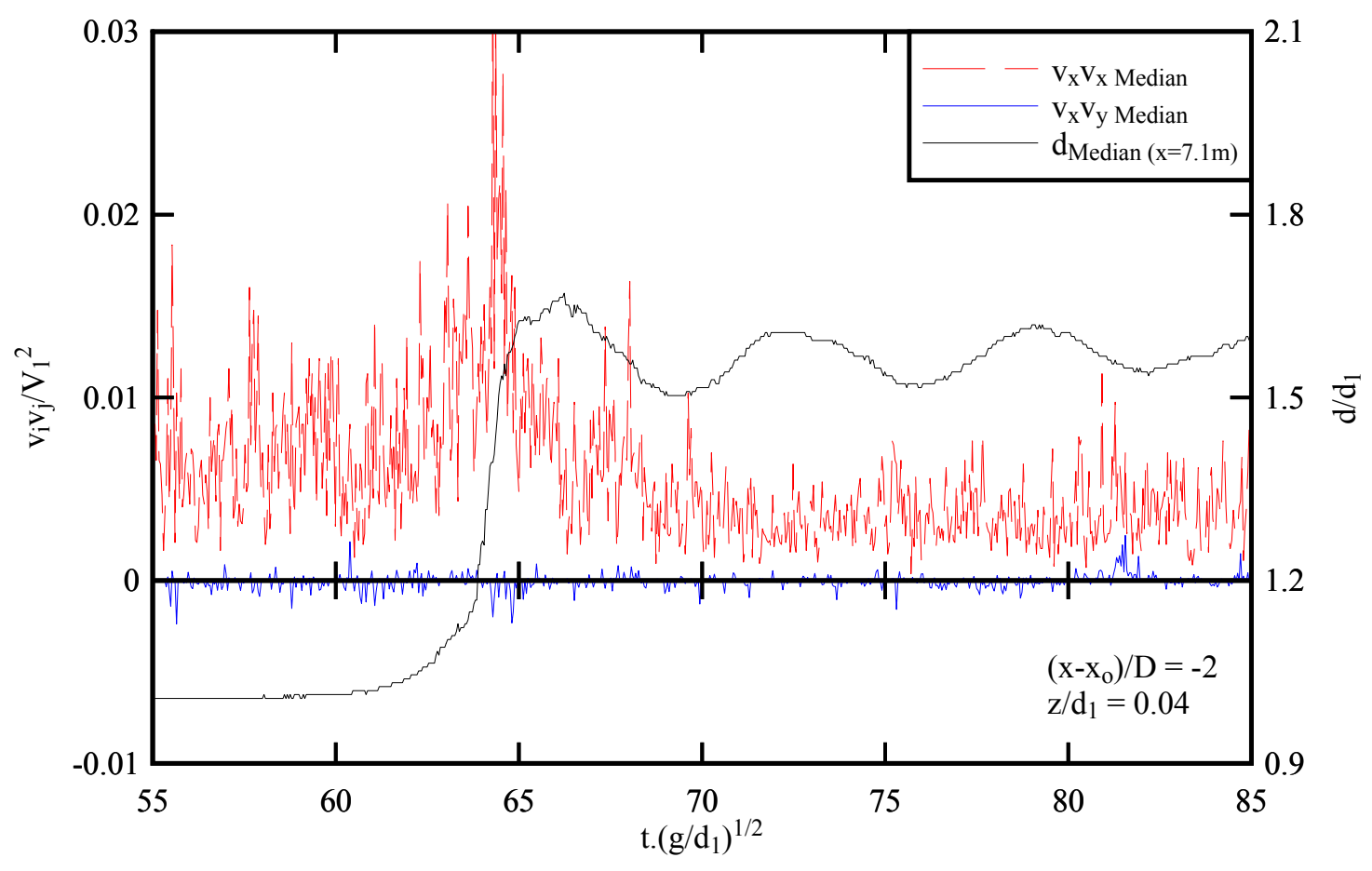


(c)

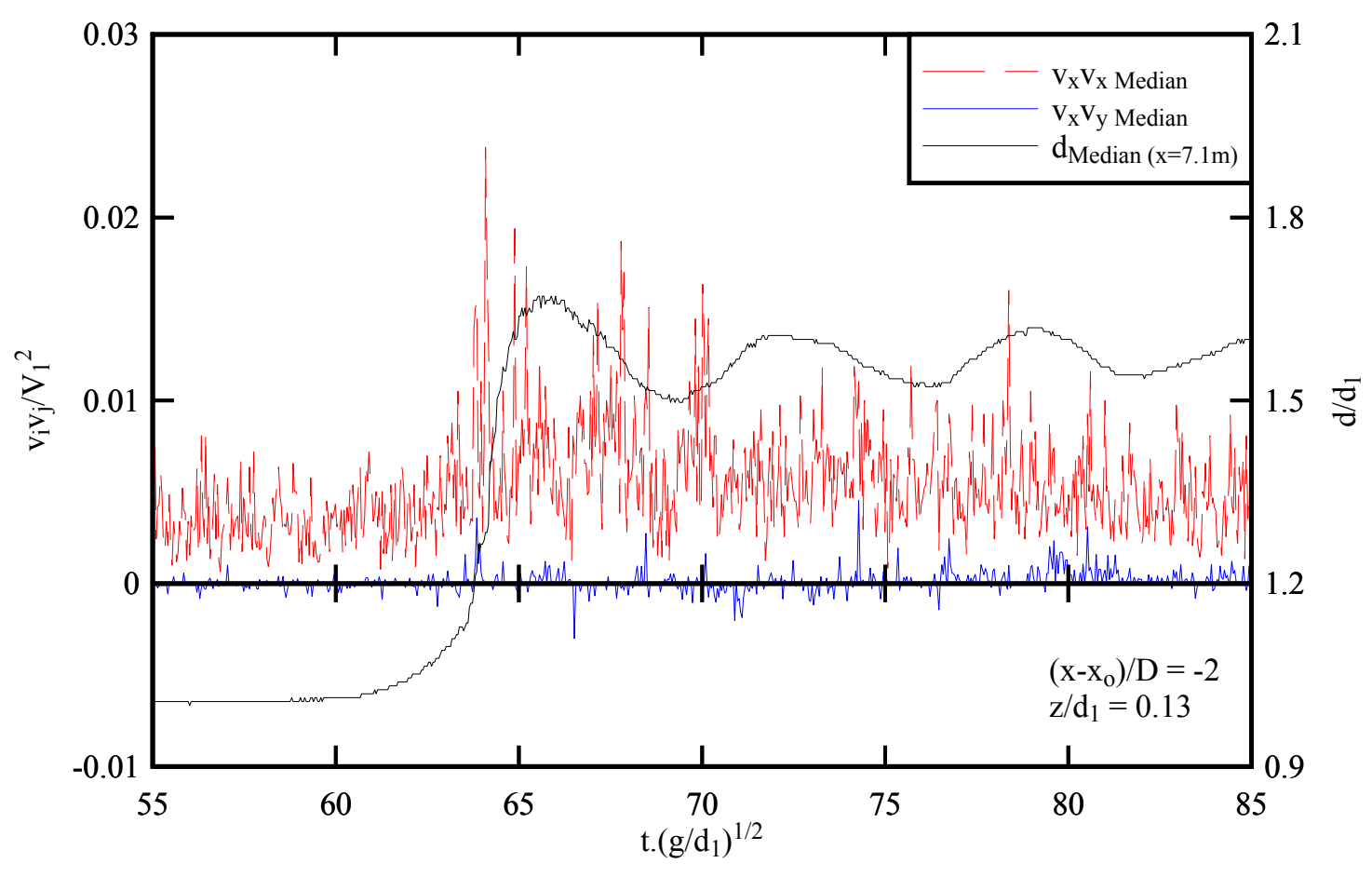

